\title{
Modeling of heat transfer attenuation by ablative gases during the Stardust re-entry
}

\author{
Alexandre Martin* \\ Department of Mechanical Engineering, University of Kentucky, Lexington, KY, 40506, USA \\ Iain D. Boyd ${ }^{\dagger}$ \\ Department of Aerospace Engineering, University of Michigan, Ann Arbor, MI, 48109, USA
}

\begin{abstract}
The great majority of modern space vehicles designed for planetary exploration use ablative materials to protect the payload against the high heating environment experienced during re-entry. In order to properly model and predict the aerothermal environment of the vehicle, it is imperative to account for the gases produced by ablation processes. In the case of charring ablators, where an inner resin is pyrolyzed at a relatively low temperature, the composition of the gas expelled into the boundary layer is complex and may lead to thermal chemical reactions that cannot be captured with simple flow chemistry models. In order to obtain better predictions, an appropriate gas flow chemistry model needs to be included in the CFD calculations. The effects of allowing such gaseous species to form in the flow field have notable repercussions on the amount of heat fluxes to the surfaces. The present study aims to examine the effects of blowing of pyrolysis gas in the outer flow field. Using six points on the Stardust entry trajectory at the beginning of the continuum regime, from $81 \mathrm{~km}$ to $69 \mathrm{~km}$, the various components of the heat flux are compared to air-only solutions. Although an additional component of the heat flux is introduced by mass diffusion, this additional term is mainly balanced by the fact that the translationalrotational component of the heat flux, the main contributor, is greatly reduced. Although a displacement of the shock is observed, it is believed that the most prominent effects are caused by a modification of the chemical composition of the boundary layer, which reduces the gas phase thermal conductivity.
\end{abstract}

\section{Nomenclature}

Symbols

$\mathrm{B}^{\prime} \quad$ Non dimensional ablation rate

D Mass diffusion coefficient

Kn Knudsen number

$\dot{m} \quad$ Mass flow rate

$p \quad$ Pressure

Subscripts

c Char

ve Vibrational-Electron-Electronic

tr Translational-Rotational

$g \quad$ Gas blown

nc Next to the wall

$\begin{array}{ll}T & \text { Temperature } \\ U, v & \text { Velocity } \\ Y & \text { Mass fraction } \\ \eta & \text { Distance normal to the wall } \\ \rho & \text { Mass density }\end{array}$

*Assistant Professor, AIAA Senior Member

$\dagger$ James E. Knott Professor of Engineering, Fellow AIAA.

$\begin{array}{ll}s & \text { Species } \\ t & \text { Time } \\ w & \text { Wall } \\ \infty & \text { Freestream }\end{array}$




\section{Introduction}

One of the most important components of a re-entry vehicle is its Thermal Protection System (TPS). Depending on the re-entry trajectory and atmospheric condition, two types of materials may be used for TPS design: ablative materials, such as the ones used on the Apollo missions, and non-ablative materials, such as the ceramic tiles used on the Space Shuttle. For most planetary exploration missions, a multi component ablative material is most frequently used. In this type of material, an inner resin is first chemically and thermally decomposed before the surface begins to react. This type of ablator, called charring or pyrolysing ablator, offers multiple advantages, like expelling a relatively cold gas in the boundary layer, or preserving the original geometry of the aerodynamic surface during re-entry.

In order to properly model the heating rates at the surface of the vehicle, the ablating boundary condition must take into account many phenomena: surface recession, wall temperature, blowing rates, gas composition, surface chemistry, etc. However, to account for the effects of the pyrolysis gas on the vehicle, the chemistry model of the flow field must include the reactions associated with the presence of this gas. Because ablation coupling is becoming an increasingly important research topic, ${ }^{1-7}$ the development of an accurate, yet usable, chemistry model is of great importance. Models have been proposed in the past ${ }^{8-10}$ but important reactions were not included, and some of the reaction rates were inappropriate or simply outdated.

Recently, a more complete model was proposed, ${ }^{11}$ which includes an extensive set of kinetic rates, taken from the combustion community. The model was reduced using 0-D sensitivity analysis over a parameter space relevant to the re-entry conditions that such a material would be exposed to. It was established that such a model was necessary to study carbon-phenolic TPS through a review of past models, which gave a wide range of results, especially when radiative heat transfer calculations were performed. ${ }^{12}$ The reduced model was later integrated into the hypersonic Computational Fluid Dynamics (CFD) code LeMANS. As a test case, results were obtained at various trajectory points of the Stardust re-entry vehicle, and the importance of accounting for ablation in flow field chemistry was highlighted. ${ }^{13}$ A later paper ${ }^{14}$ focused on the 71 $\mathrm{km}$ trajectory point, for which spectrally resolved radiative emission measurements were obtained. The experimental data was compared to the computed results, which were processed using the NEQAIR (version 99d) radiation code. ${ }^{15}$ The agreement was surprisingly good, considering the high level of assumptions and uncertainties of both the experimental data and the computations.

The current paper further analyzes the Stardust trajectory between $81 \mathrm{~km}$ and $69 \mathrm{~km}$. Six trajectory points are analyzed, and an attempt is made to identify the key aspects of the heat flux reduction caused by pyrolysis gas injection.

Finally, for validation purposes, a comparison is made with the experimental data obtained with the Echelle instrument, at an altitude of 71 and $81 \mathrm{~km}$. A good agreement is noted at $71 \mathrm{~km}$, as previously published, ${ }^{14}$ and an even better one is obtained at $81 \mathrm{~km}$. These results show the validity of the chemistry model used in the CFD code, and demonstrate that the assumptions made for calculating blowing rates and pyrolysis gas composition are reasonable.

\section{Chemistry model}

The chemistry model used in this analysis has been developed and optimized for vehicles equipped with ablative heat shields composed of PICA, re-entering in a $\mathrm{N}_{2}-\mathrm{O}_{2}$ atmosphere. ${ }^{11,13}$ The species and reaction mechanisms used in the model were carefully selected using a material response analysis. The corresponding kinetic chemistry rates were taken from the GRI-MECH model, and then reduced using a sensitivity analysis. ${ }^{11-13}$ The reduced model contains 38 species and 158 reaction rates. The selected species can be grouped into three categories; the air species:

$$
\mathrm{N}_{2}, \mathrm{O}_{2}, \mathrm{NO}, \mathrm{N}, \mathrm{O}, \mathrm{N}_{2}^{+}, \mathrm{O}_{2}^{+}, \mathrm{NO}^{+}, \mathrm{N}^{+}, \mathrm{O}^{+}, \mathrm{e}
$$

the surface species:

$$
\mathrm{H}_{2}, \mathrm{CO}, \mathrm{CH}_{4}, \mathrm{H}_{2} \mathrm{O}, \mathrm{CO}_{2}, \mathrm{OH}, \mathrm{C}_{2} \mathrm{H}_{2}, \mathrm{HCN}, \mathrm{C}_{2} \mathrm{H}, \mathrm{C}_{3}, \mathrm{CN}
$$

and the reacting species:

$$
\begin{gathered}
\mathrm{H}, \mathrm{NH}, \mathrm{HO}_{2}, \mathrm{H}_{2} \mathrm{O}_{2}, \mathrm{HCO}, \mathrm{C}, \mathrm{C}_{2}, \mathrm{CH}, \mathrm{CH}_{2}, \mathrm{CH}_{3}, \mathrm{NCO}, \mathrm{HNO} \\
\mathrm{CO}^{+}, \mathrm{CN}^{+}, \mathrm{C}^{+}, \mathrm{H}^{+}
\end{gathered}
$$


The reaction mechanisms and kinetics rates are listed in Ref. 12. The model has been validated with multiple zero-dimensional simulations performed using the $\mathrm{CHEMKIN}^{16}$ package, and compared to available experimental data that are representative of an ablative boundary layer during hypersonic re-entry. ${ }^{11}$

\section{LeMANS: an unstructured three-dimensional Navier-Stokes solver for hypersonic nonequilibrium aerothermodynamics}

The hypersonic aerothermodynamic CFD code used to analyze the chemistry model is LeMANS, a finite volume Navier-Stokes solver currently being developed at The University of Michigan. ${ }^{17-20}$ The code assumes that the rotational and translational energy modes of all species can be described by their respective temperatures $T_{r}$ and $T$, and that the vibrational energy mode and electronic energy mode of all species, as well as the free electron kinetic energy, can be described by a single temperature, $T_{v e} .{ }^{21}$ The viscous stresses are modeled assuming a Newtonian fluid, using Stokes' hypothesis, and the species mass diffusion fluxes are modeled using a modified version of Fick's law. Mixture transport properties are calculated using one of two models; the first uses Wilke's semi-empirical mixing rule with species viscosities calculated using Blottner's model and species thermal conductivities determined using Eucken's relation, and the other uses Gupta's mixing rule with species viscosities and thermal conductivities calculated using non-coulombic/coulombic collision cross section data. Heat fluxes are modeled according to Fourier's law for all temperatures. Finally, the source terms of the species conservation equations are modeled using a standard finite-rate chemistry model for reacting air in conjunction with Park's two-temperature model to account for thermal nonequilibrium effects on the reaction rates.

The code has the capability to handle meshes containing any mix of hexahedra, tetrahedra, prisms and pyramids in 3D, or triangles and quadrilaterals in 2D. Numerical fluxes between the cells are discretized using a modified Steger-Warming Flux Vector Splitting scheme, which has low dissipation and is appropriate to calculate boundary layers. A point or line implicit method is used to perform the time integration. The code has been extensively validated against experimental data, and has also been compared to other similar codes such as NASA Ames' DPLR ${ }^{22}$ and NASA Langley's LAURA. ${ }^{23}$

To account for the coupling between the flow field and the material response, the effects of ablation are added to the CFD code; therefore, a modification to the surface boundary condition is necessary. The physical values at the wall are obtained by solving the conservation of momentum equation:

$$
p_{n c}+\rho_{n c} v_{n c}^{2}=p_{w}\left(\rho_{w}, T_{w}\right)+\rho_{w} v_{w}^{2}
$$

as well as the species surface mass balance equation:

$$
\rho_{w} D_{w s} \frac{\partial Y_{w s}}{\partial \eta}=\dot{m}\left(Y_{g_{s}}-Y_{w s}\right)
$$

The surface energy balance equation does not need to be solved in the present analysis as the wall temperature, blowing rates and blowing species are imposed and not calculated.

Once values are computed for the primitive variables, the conservative quantities in the ghost cells of the boundary are set such that the flux across the wall is the required blowing flux. This blowing boundary condition has been tested over a wide range of blowing rates, assuring the robustness of the implementation. Following the same methodology for the verification and validation of NASA Ames' DPLR code ${ }^{24}$ and NASA Langley's LAURA code ${ }^{25}$ the blowing boundary of LeMANS has also been verified and validated. ${ }^{7,26}$

\section{Test-case: Stardust return capsule re-entry trajectory}

\section{IV.A. Problem description}

In order to evaluate and validate the model in LeMANS, the forebody of the Stardust return capsule is modeled during the first 10 seconds of its re-entry in the continuum regime. ${ }^{27}$ These re-entry points are chosen because they also correspond to the period where spectral emission data was measured by the Echelle instrument. ${ }^{28}$ The geometry and mesh are presented in Fig. 1 and the flow and surface parameters in Tables 1 and 2, respectively. The flow field is computed with the previously defined 38 species chemistry model, with reaction rates listed in Ref. 12. Gibb's Free Energy is used to calculate the equilibrium constants needed 
for the backward reaction rates, and the transport properties are calculated from Lennard-Jones potentials, using CHEMKIN, ${ }^{16}$ to produce individual species temperature dependent viscosity curve fits.

The values used for the surface temperature, blowing rates and gas composition are obtained with an uncoupled approach, using a combination of three NASA software tools. First, the aeroheating environment is calculated using DPLR. ${ }^{29}$ The heat transfer coefficient, the surface pressure and the freestream enthalpy are then used in the material response code, FIAT. ${ }^{30}$ The pressure and the non-dimensionalized ablation rate, $\mathrm{B}_{g}^{\prime}$ and $\mathrm{B}_{c}^{\prime}$, values predicted by FIAT are then extracted and input to the Multicomponent Ablation Thermochemistry (MAT) code. ${ }^{31}$ When given this information, MAT calculates back from the $\mathrm{B}^{\prime}$ tables the species mole fractions according to JANNAF information corresponding to the wall temperature predicted by FIAT. This procedure therefore provides input values for blowing rates, wall temperature and equilibrium species composition. It is to be noted that the equilibrium condition is computed while accounting for the boundary layer edge gas (air) and the surface material (carbon), and therefore accounts for surface ablation. The downside of this procedure is that mass is introduced at the surface as the boundary layer edge gas is considered to be injected at the surface. However, at this altitude the added mass is negligible, since the blowing rate is less than $1 \%$ of the freestream mass flux.

The values obtained through this procedure are only calculated at the stagnation point and are expected to be significantly lower elsewhere on the forebody of the vehicle. To reflect this, a temperature profile is obtained using a fully radiative equilibrium boundary condition at the wall, without ablation. The surface temperature profile is then normalized and re-applied for the ablating wall simulation, multiplied by the surface temperature at the stagnation point that is listed in Table 2. This method has been proven to give a good estimate of the surface conditions. ${ }^{27}$ For the blowing rate, a linear relation between the temperature and the mass flux is derived using the second and third columns of Table 2, and applied proportionally using the normalized surface temperature profile. The values for those two parameters are presented in Fig. 2.

\section{IV.B. Results}

The stagnation line temperatures and gas composition, as well as the heat flux components are presented in Figs. 3 to 8. Overall, for this particular trajectory, condition and material, the various species behave in the same manners, are present along the same distance, proportionally to the location of the shock. Most of the blowing species are destroyed almost immediately once they enter the flow, although $\mathrm{CO}$ and $\mathrm{OH}$ remain in relatively high concentration. These two species are important since they are strong radiators. Atomic species, $\mathrm{H}$ and $\mathrm{C}$, are created in high concentration near the boundary, as are $\mathrm{CN}$ and $\mathrm{CN}+$, which are quite important, also because of their radiative properties. As noted previously, ${ }^{13,14}$ the concentration of HNO, a species neglected in other models, is relatively high.

\section{Heat flux reduction}

In order to evaluate the degree of heat flux reduction caused by the blowing of pyrolysis species from the surface, two additional series of test cases are run for all trajectory points: the first uses a non-catalytic boundary condition, and the second a super catalytic one. In both cases, an 11 species chemistry model for air is used. As a non catalytic wall is known to underestimate the heat flux, and the super catalytic known to overestimate, the correct solution must lie in between, and those two models provide a good starting point for comparisons.

First, the effects of blowing reduction on translational-rotational energy are examined. Figures 9,10 and 11 present the translational-rotational temperature on the stagnation line, as well as the translationalrotational heat flux at the wall for altitudes of $81 \mathrm{~km}, 76 \mathrm{~km}$ and $68.9 \mathrm{~km}$, respectively. As can be seen, the first notable effect of blowing is the displacement of the shock. Even at low blowing rates $(81 \mathrm{~km})$, the shock is significantly moved away from the surface of the vehicle. This has of course a direct repercussion on the shape of the curves, and therefore affects the gradient of temperature at the wall, as can be seen in Figs. 9b) , 10b) and 11b). However, even if the heat flux is directly linked to the gradient of temperature at the wall, the gas phase conductivity also plays an impotent role. And it is for that reason that there is no direct correlation with the steepness of the gradient and the heat flux. And for that reason, it is clear that, regardless of the altitude, blowing rate and chemical species, the most important effect that contributes to heat flux reduction is the composition of the gas in the boundary layer.

It is also interesting to compare the super catalytic and non catalytic curves. Although the super-catalytic boundary conditions provide a larger total heat flux, the changes in composition of the boundary layer result 
in a significant reduction of the translational-rotational component, even though the gradient would tend to suggest otherwise.

The same analysis can be performed on the vibrational-electron-electronic component of the heat fluxes. The results are presented in Fig. 12. As with the translational-rotational temperature, the change in the chemical composition of the boundary layer results in a significant reduction in the heat flux. However, the effects are not as straightforward as for the other conductive heat flux, as the amount of species with vibrational (and electronic) degrees of freedom has a direct impact on the energy distribution. The heat fluxes due to mass diffusion are shown in Fig. 13. As expected, the super-catalytic wall results in an artificially high heat flux, and those values are significantly reduced when a blowing boundary condition is applied. That figure also shows that, as expected, the reduction in the translational-rotation heat fluxes are directly proportional to the mass diffusion heat flux. By also comparing with Fig. 2b), it can be seen that the mass diffusion heat flux is directly proportional to the pyrolysis gas mass flow. Again, this represents a conclusion that is far from being surprising.

Finally, in Fig. 14, the relative contributions of each component of the heat flux are plotted for all trajectory points. It can be seen that for the trajectory points chosen for this analysis, the translationalrotational component contributes the most. We can also observe that the amount of blowing has a direct and linear influence on the translational-rotational heat flux. This result clearly shows that an increase in blowing rates has a major impact on the overall heat flux, and that although it translates into an increase in mass diffusion heat flux, it does not become the dominant component.

\section{Radiative emission}

As additional results, and in an attempt to validate the current methodology, the spectral line emissions for $\mathrm{CN}$ are compared to the experimental data obtained by the Echelle instrument ${ }^{28}$ at high altitude (81 $\mathrm{km})$ and lower altitude $(71 \mathrm{~km})$. The radiative emission calculation is performed along the stagnation line of a converged flow field solution using the non-equilibrium radiation code NEQAIR2009 (version 6). ${ }^{32}$ The temperatures and species concentrations used as inputs NEQAIR are presented in Figs. 3 and 7 and the spectral emissions are presented in Fig. 15. As was previously reported, the lower altitude trajectory point reasonably matches the experimental data, as the discrepancy remains within one order of magnitude. As seen in Ref. 14, the difference would be even less if a spatially resolved input was used in NEQAIR, instead of simply the stagnation line. The high altitude trajectory point $(81 \mathrm{~km})$ gives an even better comparison. For those two results, the CN calculation was run independently of the air calculations, and in the latter case, the $\mathrm{N} 2+$ system was omitted because of known issues with the software.

\section{Conclusion}

In order to evaluate the mechanism of heat flux reduction caused by pyrolysis gas blowing, a comprehensive chemistry model for computing the flow around a re-entry vehicle using an ablative heat shield has been used in a CFD code. The species used in the model have been selected with careful consideration of the flow physics, and the reactions have been evaluated and chosed from various sources in the literature. The model has been reduced to a more manageable number of species and reactions, using a zero-dimensional sensitivity analysis, and was validated using various experimental results

The CFD software used to model the flow field is the hypersonic non-equilibrium code LeMANS, which was adequately modified to allow flow through the surface of the vehicle. As a test case, the Stardust re-entry vehicle was used. This vehicle has been extensively studied in the past and is relatively simple to model. The first six trajectory points corresponding to the continuum regime were chosen, as experimental data is available in the form of spectral radiative emission gathered by the Echelle instrument. ${ }^{28}$

As expected, the convective heat flux predicted using the carbon-phenolic-in-air chemistry model was significantly reduced relative to the prediction obtained using the air chemistry model. The species concentrations along the stagnation line were also presented and it was shown that at chemical equilibrium conditions, most species blown from the surface immediately react in the flowfield and are transformed. These results clearly indicate the need to use an appropriate chemistry model in the flow field, and that the chemistry model should be significantly different than that used to model pyrolysis gas behavior inside the TPS. Also, it was observed that the blowing rates were directly proportional to the mass diffusion heat flux, which in turn was directly proportional to the reduction of the translational-rotational conduction heat flux 
component. It was also noted that the main source of heat flux reduction is by the translational-rotational conduction component, for all trajectory points. This clearly indicates that the chemical composition of the boundary layer is of great importance, and that the diffusion coefficients of each species, as well as the mixing rules, must be calculated with great care.

Finally, the flow field solution was used to perform analysis of the CN radiative spectral emission using NEQAIR. The result was compared to the experimental data obtained by the Echelle instrument ${ }^{28}$ at the $81 \mathrm{~km}$ and $71 \mathrm{~km}$ trajectory points. The computed results were very close to the observed values, which provides increased confidence in the carbon-phenolic-in-air chemistry model, and the overall approach.

\section{Acknowledgments}

Financial support for this work was provided in part by NASA SBIR Phase-2 Award NNX10CC53P. The authors would also like to thank Dr. Erin D. Farbar, from the University of Michigan, as well as Dr. Mike Wright, Dr. Ioana Cozmuta, Dr. David Hash, Dr. Nagi Mansour, Dr. Mike Barnhardt, Dr. Jean Lachaud and Dr. Tahir Gökçen from NASA Ames Research Center for numerous insightful discussions.

\section{References}

${ }^{1}$ Suzuki, T., Sawada, K., Yamada, T., and Inatani, Y., "Experimental and Numerical Study of Pyrolysis Gas Pressure in Ablating Test Piece," Journal of Thermophysics and Heat Transfer, Vol. 19, No. 3, July-September 2005, pp. $266-272$.

${ }^{2}$ Dec, J. A. and Braun, R. D., "An Approximate Ablative Thermal Protection System Sizing Tool for Entry System Design," 44th AIAA Aerospace Sciences Meeting and Exhibit, No. AIAA 2006-780, Reno, NV, 9-12 January 2006.

${ }^{3}$ Ayasoufi, A., Rahmani, R. K., Cheng, G., Koomullil, R., and Neroorkar, K., "Numerical Simulation of Ablation for Reentry Vehicles," 9th AIAA/ASME Joint Thermophysics and Heat Transfer Conference, No. AIAA 2006-2908, San Francisco, CA, June 5-8 2006.

${ }^{4}$ Amar, A. J., Blackwell, B. F., and Edward, J. R., "One-Dimensional Ablation with Pyrolysis Gas Flow Using a Full Newton's Method and Finite Control Volume Procedure," 39th AIAA Thermophysics Conference, No. AIAA-2007-4535, Miami, FL, 25-28 June 2007.

${ }^{5}$ Milos, F. and Chen, Y.-K., "Two-Dimensional Ablation, Thermal Response and Sizing Program for Pyrolyzing Ablators," 46th AIAA Aerospace Sciences Meeting and Exhibit, AIAA-2008-1223, Reno, NV, Jan. 7-10 2008.

${ }^{6}$ Venkatachari, B. S., Cheng, G. C., Koomullil, R. P., and Ayasoufi, A., "Computational Tools for Re-entry Aerothermodynamics - Part II. Surface Ablation," 46th AIAA Aerospace Sciences Meeting and Exhibit, AIAA-2008-1218, Reno, NV, Jan. 7-10 2008.

${ }^{7}$ Martin, A. and Boyd, I. D., "Simulation of pyrolysis gas within a thermal protection system," 40th AIAA Thermophysics Conference, No. AIAA-2008-3805, Seattle, WA, June 23-26 2008.

${ }^{8}$ Park, C., Jaffe, R. L., and Partridge, H., "Chemical-Kinetic Parameters of Hyperbolic Earth Entry," Journal of Thermophysics and Heat Transfer, Vol. 15, No. 1, January- March 2001, pp. 76-90.

${ }^{9}$ Suzuki, K., Kubota, H., Fujita, K., and Abe, T., "Chemical nonequilibrium ablation analysis of MUSES-C super-orbital reentry capsule," 32nd AIAA Thermophysics Conference, No. AIAA-1997-2481, June 23-25 1997.

${ }^{10}$ Olynick, D., Chen, Y.-K., and Tauber, M. E., "Aerothermodynamics of the Stardust Sample Return Capsule," Journal of Spacecraft and Rockets, Vol. 36, No. 3, May-June 1999, pp. 442-462.

${ }^{11}$ Martin, A., Boyd, I. D., Cozmuta, I., and Wright, M. J., "Chemistry model for ablating carbon-phenolic material during atmospheric re-entry," 48th AIAA Aerospace Sciences Meeting and Exhibit, No. AIAA-2010-1175, Orlando, FL, January 2010.

${ }_{12}$ Martin, A. and Boyd, I. D., "Assessment of carbon-phenolic-in-air chemistry models for atmospheric re-entry," 10th AIAA/ASME Joint Thermophysics and Heat Transfer Conference, No. AIAA-2010-4656, Chicago, IL, June 28th to July 1st 2010.

${ }^{13}$ Martin, A. and Boyd, I. D., "CFD Implementation of a novel carbon-phenolic-in-air chemistry model for atmospheric re-entry," 49th AIAA Aerospace Sciences Meeting and Exhibit, No. AIAA 2011-143, Orlando, FL, January 4-7 2011.

${ }^{14}$ Martin, A., Farbar, E. D., and Boyd, I. D., "Numerical modeling of the CN spectral emission of the Stardust re-entry vehicle," 42nd AIAA Thermophysics Conference, No. AIAA-2011-3125, Honolulu, HI, June 27-30 2011.

${ }^{15}$ Whiting, E. E., Park, C., Liu, Y., Arnold, J. O., and Paterson, J. A., "NEQAIR96, Nonequilibrium and Equilibrium Radiative Transport and Spectra Program: User's Manual," Reference Publication 1389, NASA, December 1996.

${ }^{16}$ Kee, R. J., Rupley, F. M., Miller, J. A., Coltrin, M. E., Grcar, J. F., Meeks, E., Moffat, H. K., Lutz, A. E., Dixon-Lewis, G., Smooke, M. D., Warnatz, J., Evans, G. H., Larson, R. S., Mitchell, R. E., Petzold, L. R., Reynolds, W. C., Caracotsios, M., Stewart, W. E., Glarborg, P., Wang, C., McLellan, C. L., Adigun, O., Houf, W., Chou, C. P., Miller, S. F., Ho, P., Young, P. D., Young, D. J., Hodgson, D. W., Petrova, M. V., and Puduppakkam, K. V., "CHEMKIN, Release 4.1," 2006.

${ }^{17}$ Scalabrin, L. C. and Boyd, I. D., "Numerical Simulations of the FIRE-II Convective and Radiative Heating Rates," 39th AIAA Thermophysics Conference, No. AIAA-2007-4044, Miami, FL, 25 - 28 June 2007.

${ }^{18}$ Scalabrin, L. C., Numerical Simulation of Weakly Ionized Hypersonic Flow Over Reentry Capsules., Ph.D. thesis, The University of Michigan, Ann Arbor, MI, 2007.

${ }^{19}$ Scalabrin, L. C. and Boyd, I. D., "Development of an Unstructured Navier-Stokes Solver for Hypersonic Nonequilibrium Aerothermodynamics," 38th AIAA Thermophysics Conference, No. AIAA-2005-5203, Toronto, Ontario, June 6-9 2005. 
${ }^{20}$ Scalabrin, L. C. and Boyd, I. D., "Numerical Simulation of Weakly Ionized Hypersonic Flow for Reentry Configurations," 9th AIAA/ASME Joint Thermophysics and Heat Transfer Conference, No. AIAA-2006-3773, San Francisco, CA, June 5-8 2006.

${ }^{21}$ Holman, J. P., Heat transfer, Mc Graw-Hill : Publishing Company, 1990.

${ }^{22}$ Wright, M. J., Candler, G. V., and Bose, D., "Data-Parallel Line Relaxation method for the Navier-Stokes equations," AIA A Journal, Vol. 36, No. 9, September 1998, pp. 1603-1609.

${ }^{23}$ Gnoffo, P. A., "Upwind-Biased, Point-implicit Relaxation Strategies for Viscous Hypersonic Flows," 9th AIAA Computational Fluid Dynamics Conference, No. AIAA-1989-1972-CP, Buffalo, NY, June 13-15 1989, pp. 415-425.

${ }^{24}$ Martinelli, S. and Ruffin, S., "Validation Process for Blowing and Transpiration-Cooling in DPLR," 39th AIAA Thermophysics Conference, No. AIAA-2007-4255, 2007, p. 9.

${ }^{25}$ Thompson, R. A. and Gnoffo, P. A., "Implementation of a Blowing Boundary Condition in the LAURA Code," 46th AIAA Aerospace Sciences Meeting and Exhibit, No. AIAA-2008-1243, Reno, NV, Jan. 7-10 2008.

${ }^{26}$ Martin, A. and Boyd, I. D., "Implicit implementation of material response and moving meshes for hypersonic re-entry ablation," 47th AIAA Aerospace Sciences Meeting and Exhibit, No. AIAA-2009-0670, Orlando, FL, Jan. 5-8 2009.

${ }^{27}$ Trumble, K. A., Cozmuta, I., Sepka, S., and Jenniskens, P., "Post-flight Aerothermal Analysis of the Stardust Sample Return Capsule," 46th AIAA Aerospace Sciences Meeting and Exhibit, AIAA-2008-1201, Reno, NV, Jan. 7-10 2008.

${ }^{28}$ Jenniskens, P., "Observations of the STARDUST Sample Return Capsule Entry with a Slit-less Echelle Spectrograph," 46th AIAA Aerospace Sciences Meeting and Exhibit, Reno, NV, 7-10 January 2008.

${ }^{29}$ NASA Ames Research Center, DPLR Package Users Guide, 3rd ed.

${ }^{30}$ Chen, Y.-K. and Milos, F. S., "Ablation and Thermal Response Program for Spacecraft Heatshield Analysis," Journal of Spacecraft and Rockets, Vol. 36, No. 3, May-June 1999, pp. 475-483.

${ }^{31}$ Milos, F. S. and Chen, Y.-K., "Comprehensive model for multicomponent ablation thermochemistry," 35th Aerospace Sciences Meeting and Exhibit, No. AIAA-1997-141, Reno, NV, Jan. 6-9 1997.

${ }^{32}$ Palmer, G. E., "Personal communication," 2011. 
Table 1. Free stream conditions for the Echelle period of the trajectory of the Stardust re-entry vehicle

\begin{tabular}{cccccccc}
\hline \hline $\begin{array}{c}\text { Altitude } \\
{[\mathrm{s}]}\end{array}$ & $\begin{array}{c}\text { Time } \\
{[\mathrm{km}]}\end{array}$ & $\begin{array}{c}U_{\infty} \\
{[\mathrm{km} / \mathrm{s}]}\end{array}$ & $\begin{array}{c}T_{\infty} \\
{[\mathrm{K}]}\end{array}$ & $\begin{array}{c}\rho_{\infty} \\
{\left[\mathrm{kg} / \mathrm{m}^{3}\right]}\end{array}$ & $Y_{N_{2}}$ & $Y_{O_{2}}$ & $\mathrm{Kn}$ \\
\hline 81.0 & 34 & 12.4 & 218. & $1.27 \times 10^{-4}$ & 0.763 & 0.237 & 0.00645 \\
78.5 & 36 & 12.3 & 218. & $1.87 \times 10^{-4}$ & 0.763 & 0.237 & 0.00432 \\
76.0 & 38 & 12.3 & 219. & $2.72 \times 10^{-4}$ & 0.763 & 0.237 & 0.00292 \\
73.5 & 40 & 12.2 & 220. & $3.92 \times 10^{-4}$ & 0.763 & 0.237 & 0.00203 \\
71.2 & 42 & 12.1 & 222. & $5.55 \times 10^{-4}$ & 0.763 & 0.237 & 0.00145 \\
68.9 & 44 & 11.9 & 224. & $7.72 \times 10^{-4}$ & 0.763 & 0.237 & 0.00105 \\
\hline \hline
\end{tabular}

Table 2. Wall conditions at the stagnation point for the Echelle period of the trajectory of the Stardust re-entry vehicle

\begin{tabular}{ccccccc}
\hline \hline $\begin{array}{c}\text { Altitude } \\
{[\mathrm{km}]}\end{array}$ & $\begin{array}{c}T_{w} \\
{[\mathrm{~K}]}\end{array}$ & $\begin{array}{c}\dot{m}_{w} \\
{\left[\mathrm{~kg} / \mathrm{m}^{2} / \mathrm{s}\right]}\end{array}$ & $Y_{N_{2}}$ & $Y_{\mathrm{CO}}$ & $Y_{\mathrm{H}_{2}}$ & $Y_{\mathrm{H}_{2} \mathrm{O}}$ \\
\hline 81.0 & 2890. & 0.0214 & $6.16 \times 10^{-1}$ & $2.32 \times 10^{-1}$ & $1.52 \times 10^{-2}$ & $6.85 \times 10^{-2}$ \\
78.5 & 2970. & 0.0264 & $6.14 \times 10^{-1}$ & $2.34 \times 10^{-1}$ & $1.52 \times 10^{-2}$ & $7.32 \times 10^{-2}$ \\
76.0 & 3070. & 0.0299 & $6.49 \times 10^{-1}$ & $1.75 \times 10^{-1}$ & $1.08 \times 10^{-2}$ & $4.88 \times 10^{-2}$ \\
73.5 & 3150. & 0.0378 & $6.54 \times 10^{-1}$ & $1.65 \times 10^{-1}$ & $9.38 \times 10^{-3}$ & $5.41 \times 10^{-2}$ \\
71.2 & 3240. & 0.0453 & $6.75 \times 10^{-1}$ & $1.23 \times 10^{-1}$ & $5.76 \times 10^{-3}$ & $5.23 \times 10^{-2}$ \\
68.9 & 3310. & 0.0549 & $6.78 \times 10^{-1}$ & $1.25 \times 10^{-1}$ & $7.21 \times 10^{-3}$ & $3.08 \times 10^{-2}$ \\
\hline \hline
\end{tabular}

\begin{tabular}{ccccccc}
\hline \hline $\begin{array}{c}\text { Altitude } \\
{[\mathrm{km}]}\end{array}$ & $Y_{\mathrm{OH}}$ & $Y_{O}$ & $Y_{\mathrm{CO}_{2}}$ & $Y_{N O}$ & $Y_{O_{2}}$ & $Y_{N}$ \\
\hline 81.0 & $1.94 \times 10^{-2}$ & $1.24 \times 10^{-2}$ & $2.72 \times 10^{-2}$ & $4.93 \times 10^{-3}$ & $5.05 \times 10^{-3}$ & 0.00 \\
78.5 & $1.72 \times 10^{-2}$ & $9.18 \times 10^{-3}$ & $2.94 \times 10^{-2}$ & $4.38 \times 10^{-3}$ & $4.02 \times 10^{-3}$ & 0.00 \\
76.0 & $3.21 \times 10^{-2}$ & $3.75 \times 10^{-2}$ & $1.92 \times 10^{-2}$ & $1.22 \times 10^{-3}$ & $1.52 \times 10^{-2}$ & 0.00 \\
73.5 & $3.19 \times 10^{-2}$ & $3.33 \times 10^{-2}$ & $2.30 \times 10^{-2}$ & $1.30 \times 10^{-2}$ & $1.72 \times 10^{-2}$ & 0.00 \\
71.2 & $3.30 \times 10^{-2}$ & $3.68 \times 10^{-2}$ & $2.70 \times 10^{-2}$ & $1.74 \times 10^{-2}$ & $2.99 \times 10^{-2}$ & 0.00 \\
68.9 & $3.71 \times 10^{-2}$ & $6.46 \times 10^{-2}$ & $1.22 \times 10^{-2}$ & $2.08 \times 10^{-2}$ & $2.44 \times 10^{-2}$ & $7.84 \times 10^{-5}$ \\
\hline \hline
\end{tabular}




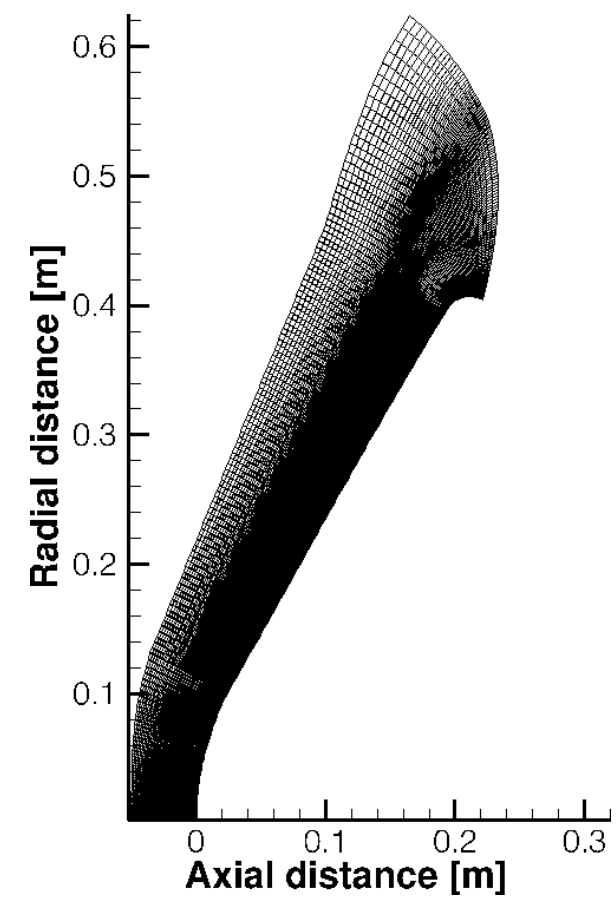

(a) Geometry and overall mesh

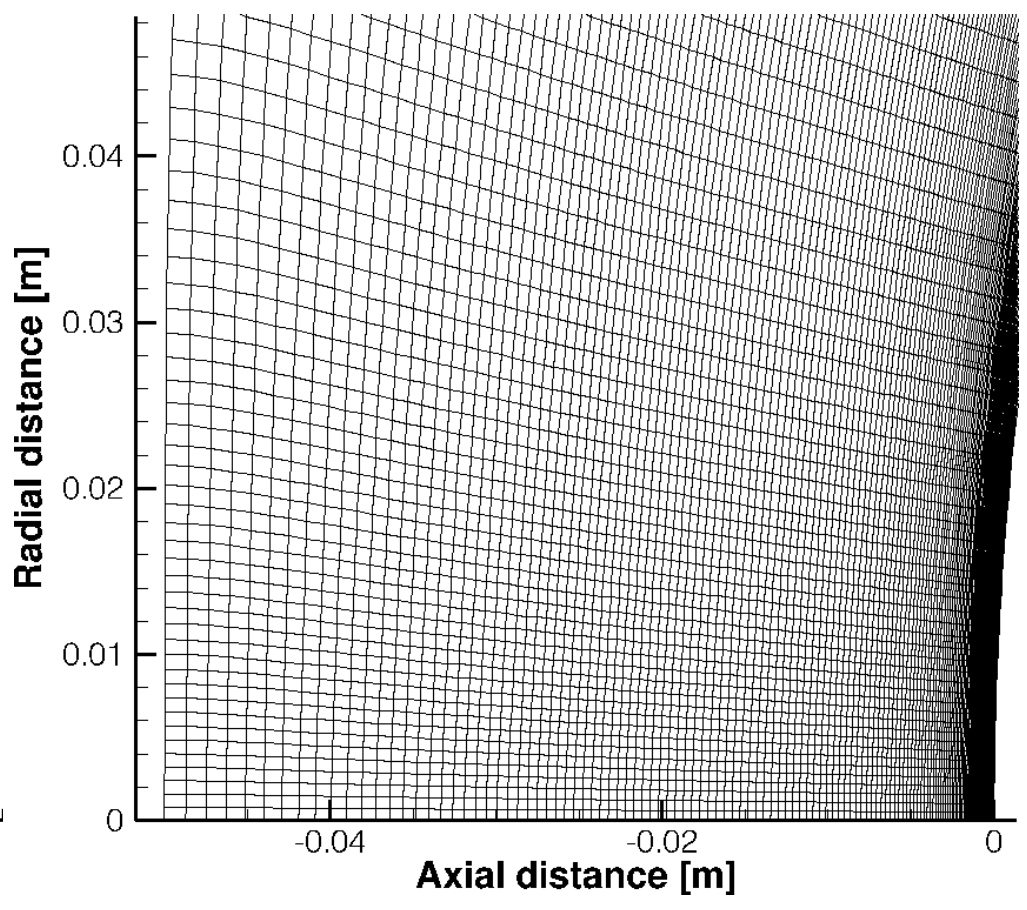

(b) Stagnation region mesh

Figure 1. Geometry and mesh of the Stardust re-entry capsule, used for the chemistry model comparison

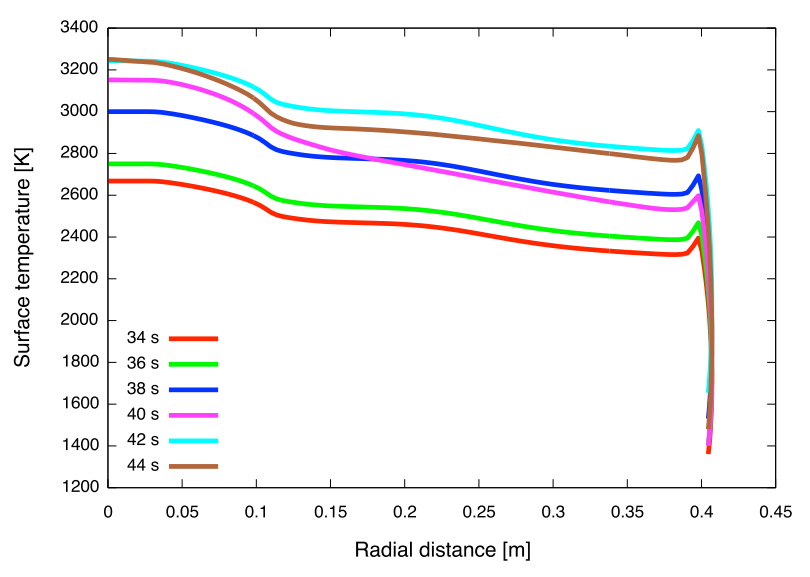

(a) Surface temperature

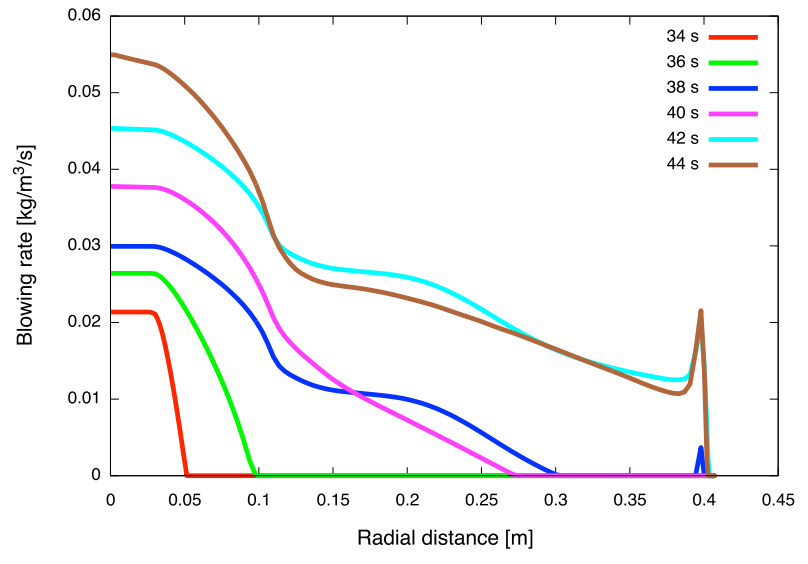

(b) Surface blowing rate

Figure 2. Surface temperature and blowing rates at $42 \mathrm{~s}(71 \mathrm{~km})$ for Stardust 


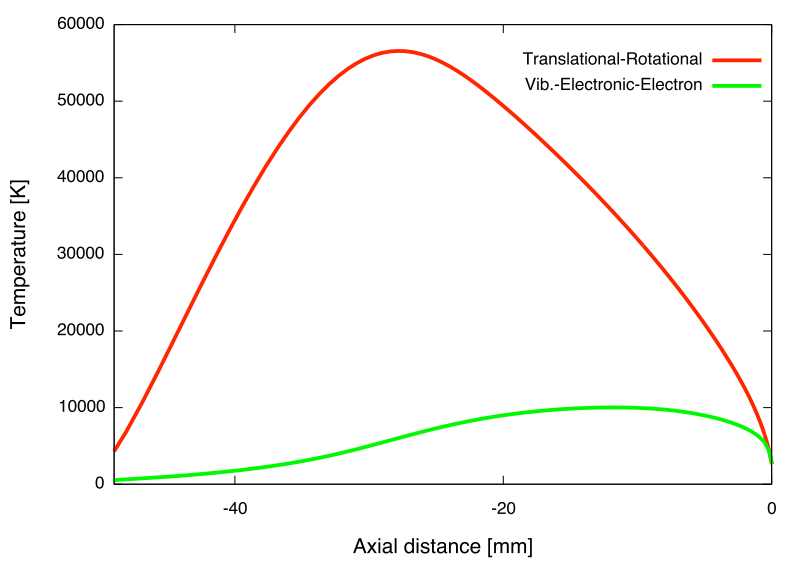

(a) Stagnation line temperatures

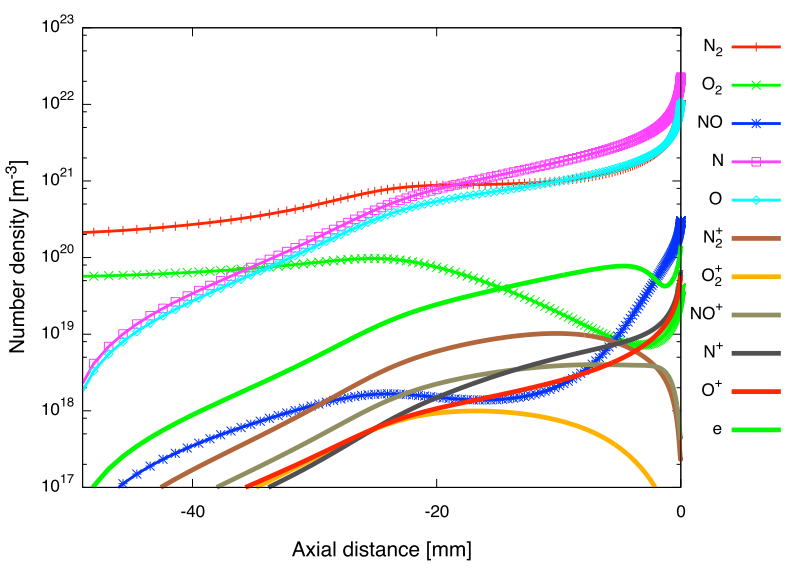

(c) Air species

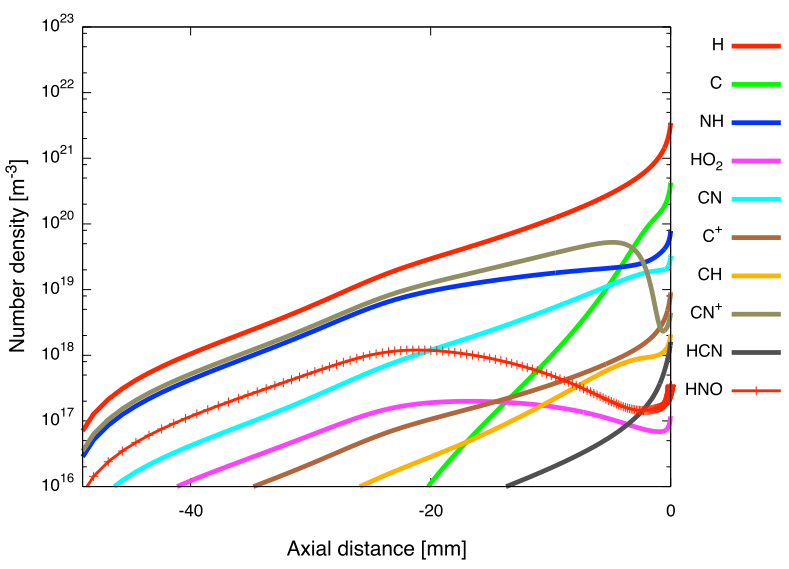

(e) High concentration species

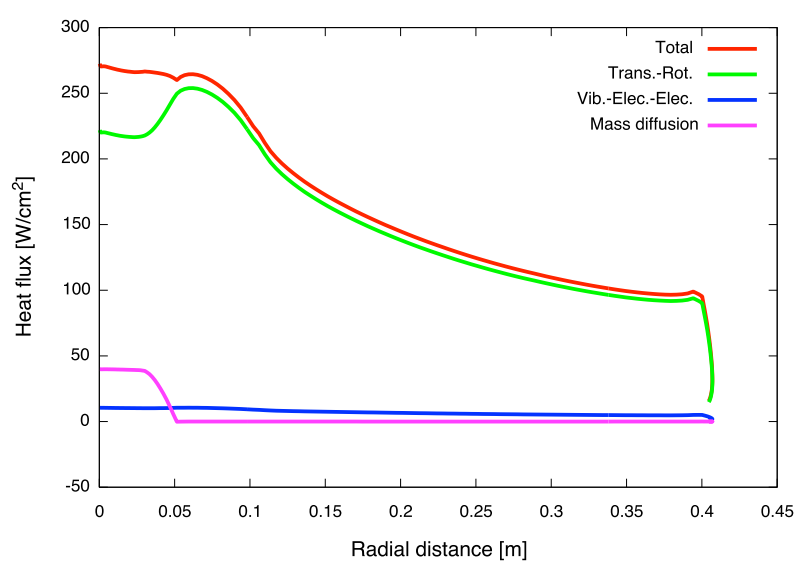

(b) Surface heat fluxes

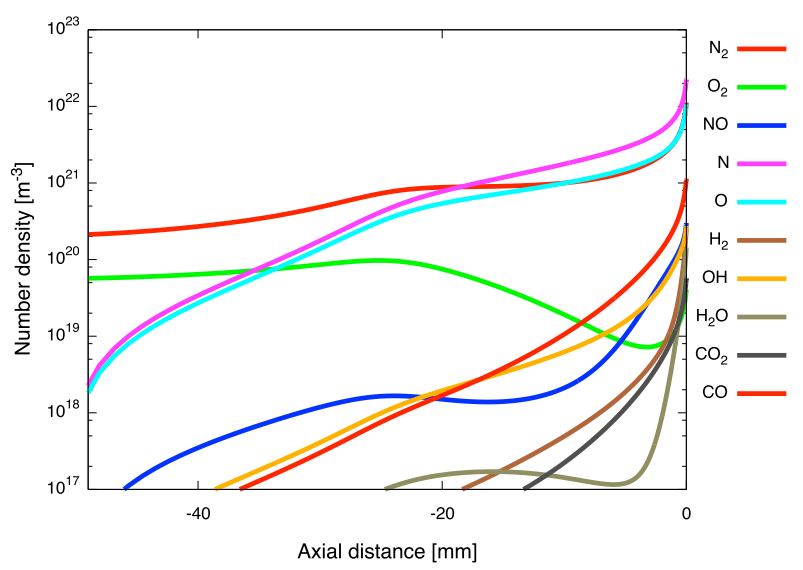

(d) Surface blowing species

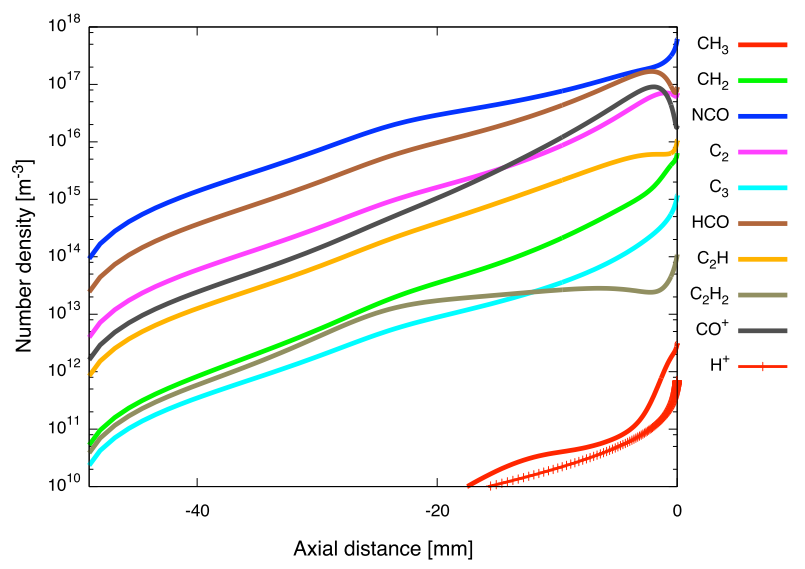

(f) Low concentration species

Figure 3. Species concentrations along the stagnation line for the Stardust re-entry vehicle at an altitude of $81 \mathrm{~km}(34$ $s$ into re-entry) 


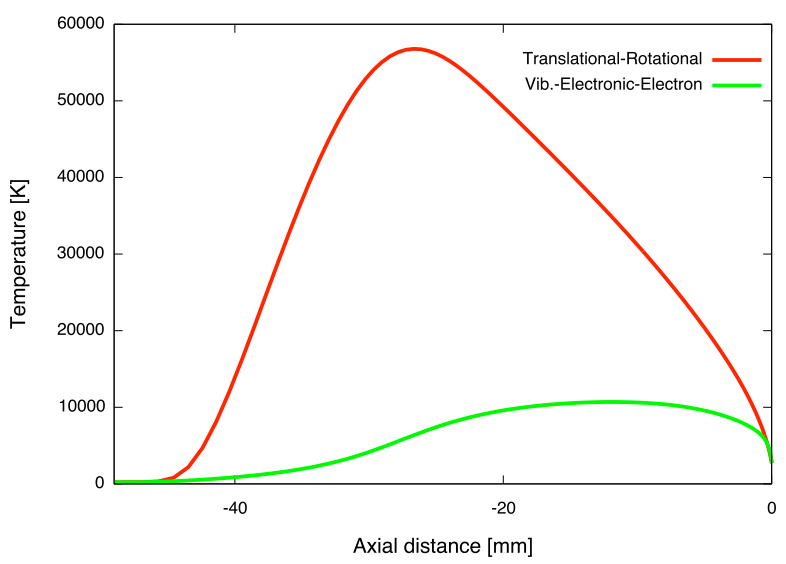

(a) Stagnation line temperatures

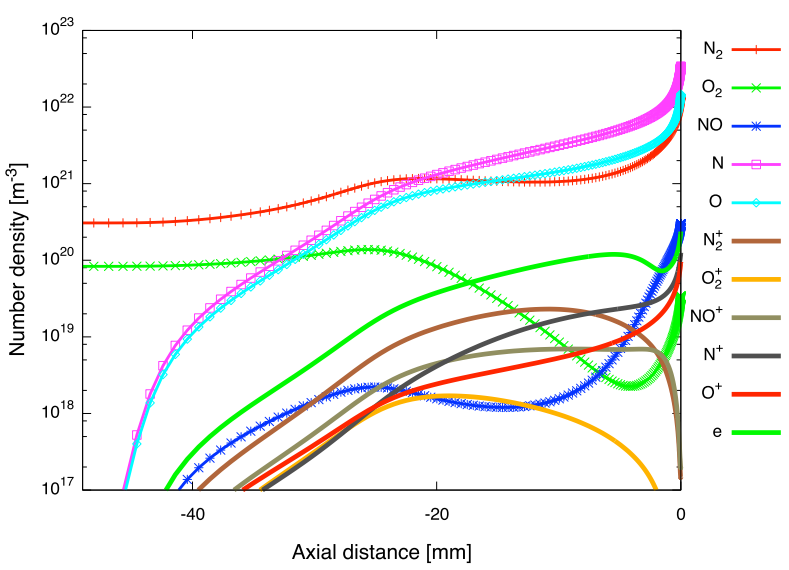

(c) Air species

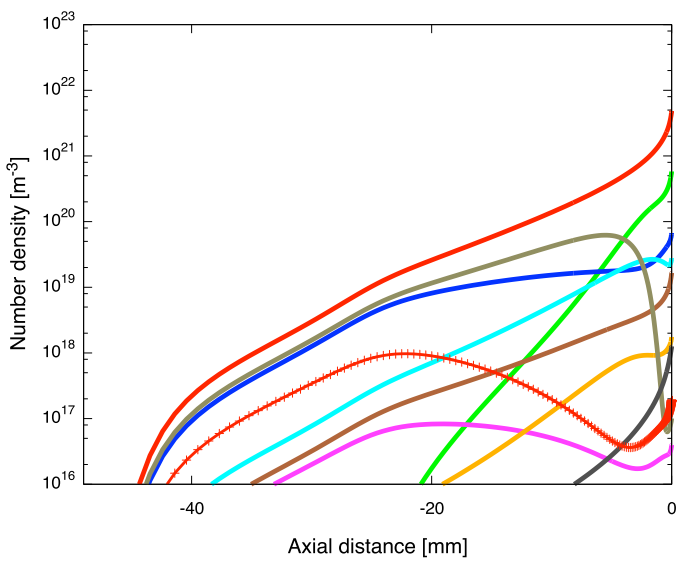

(e) High concentration species

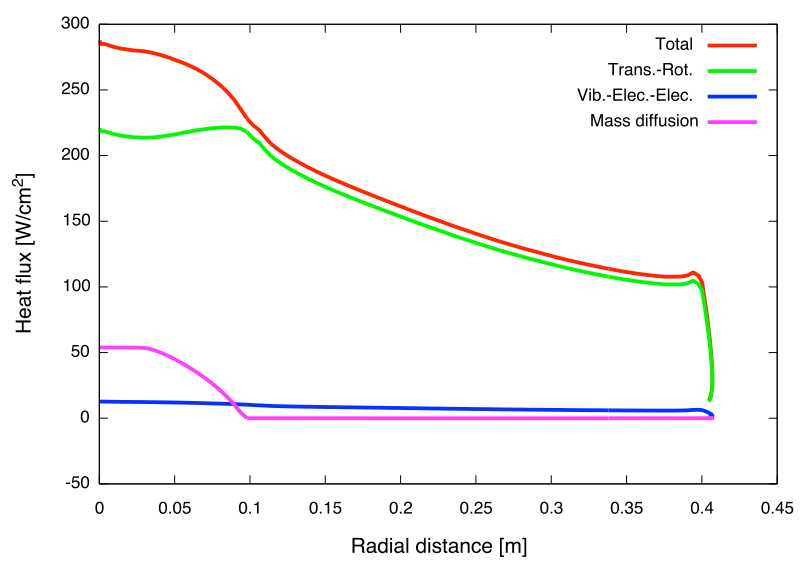

(b) Surface heat fluxes

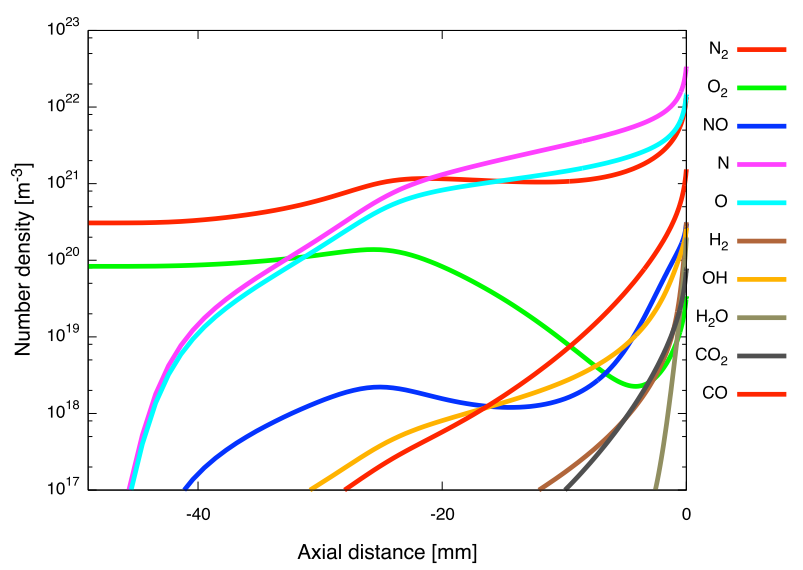

(d) Surface blowing species

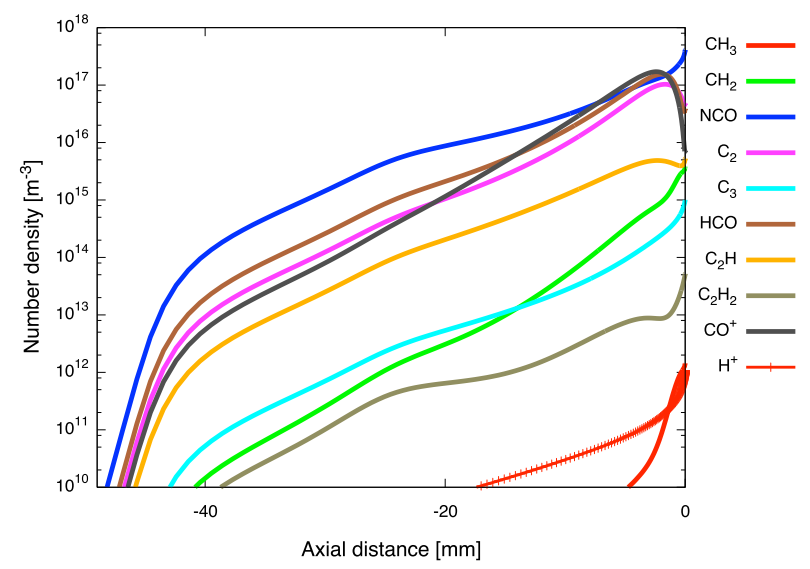

(f) Low concentration species

Figure 4. Species concentrations along the stagnation line for the Stardust re-entry vehicle at an altitude of $78.5 \mathrm{~km}$ (36 s into re-entry) 


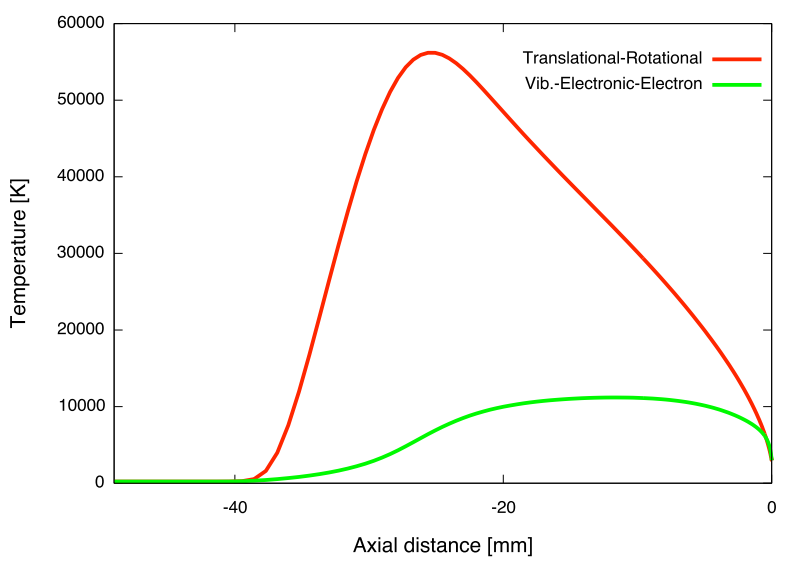

(a) Stagnation line temperatures

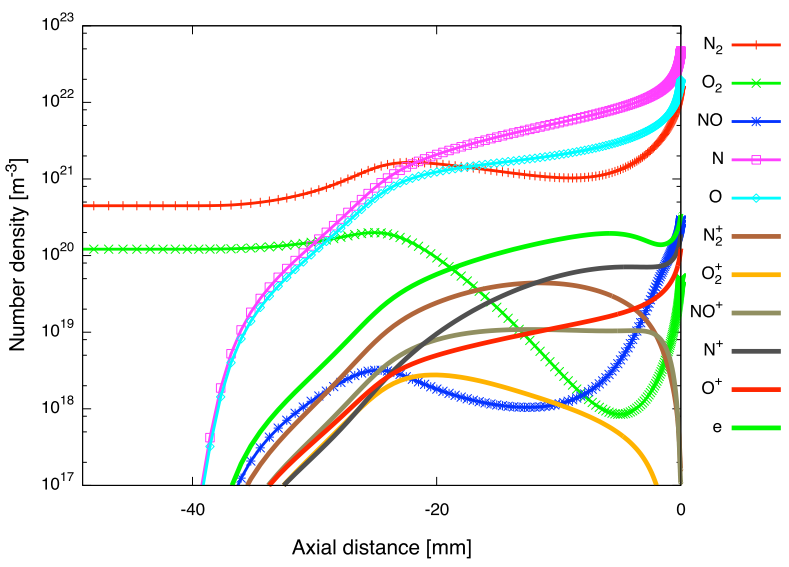

(c) Air species

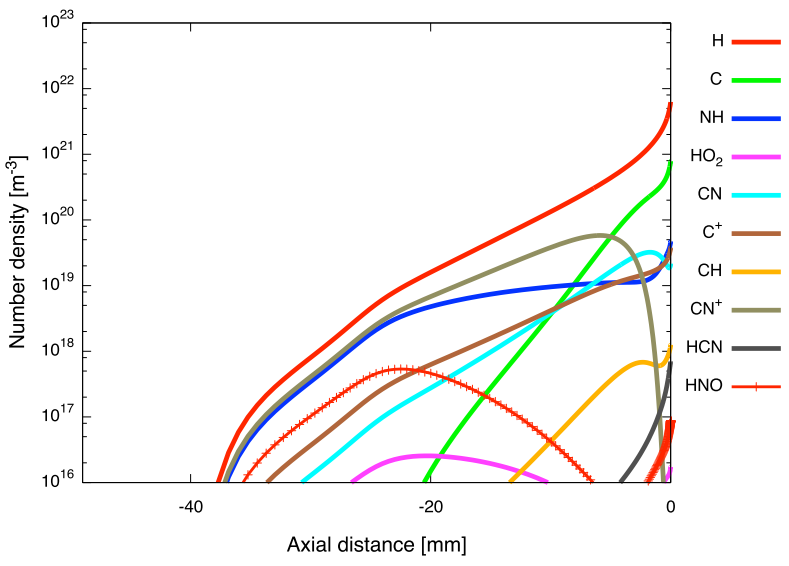

(e) High concentration species

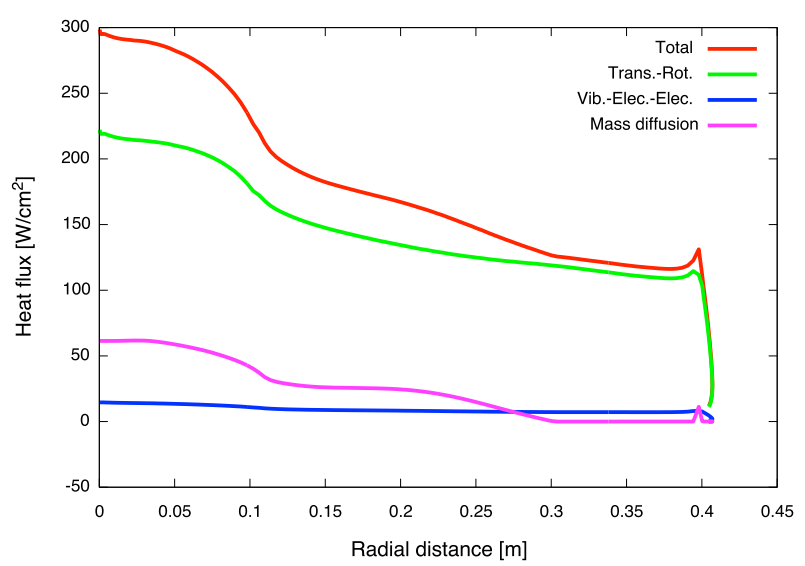

(b) Surface heat fluxes

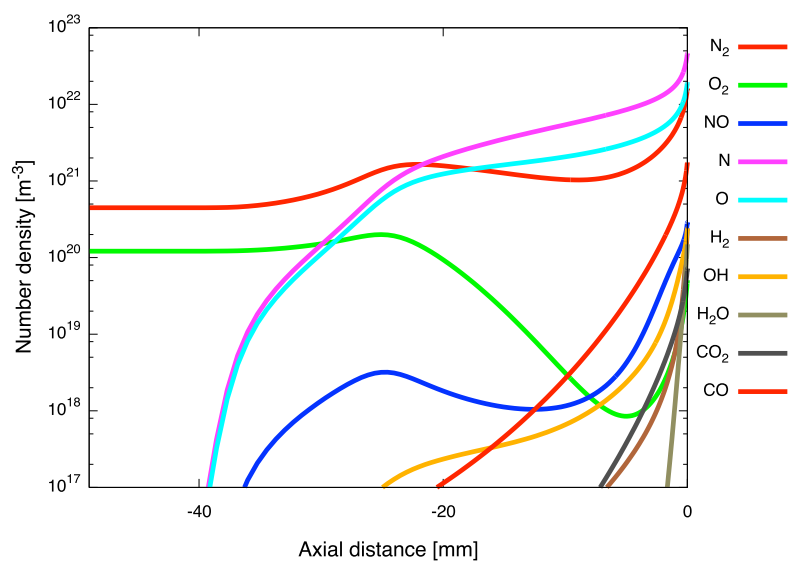

(d) Surface blowing species

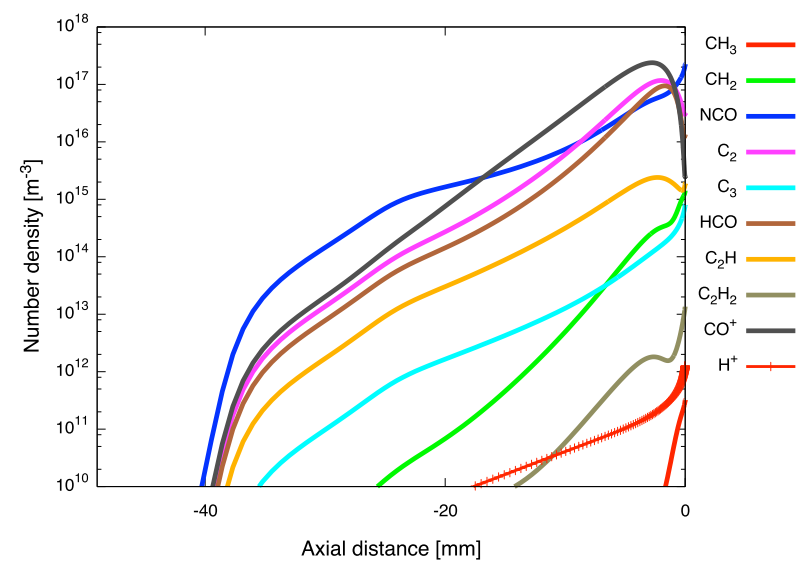

(f) Low concentration species

Figure 5. Species concentrations along the stagnation line for the Stardust re-entry vehicle at an altitude of $76 \mathrm{~km}(38$ $\mathrm{s}$ into re-entry) 


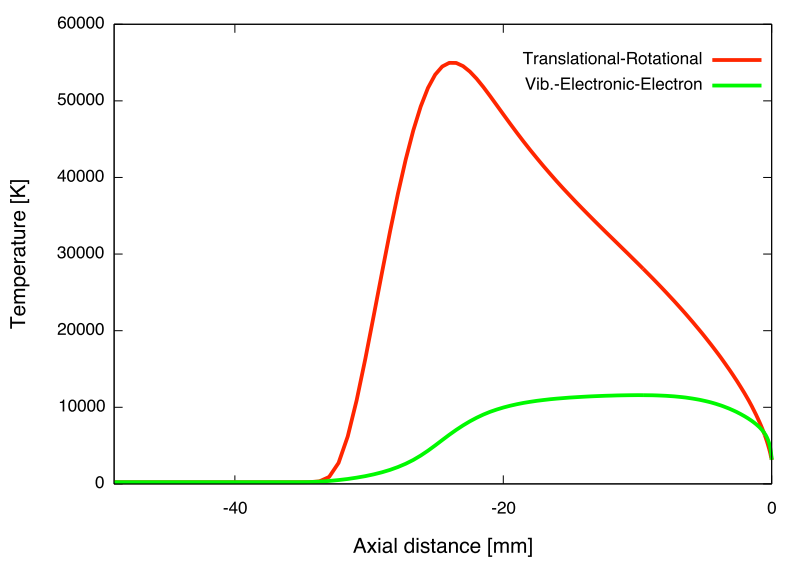

(a) Stagnation line temperatures

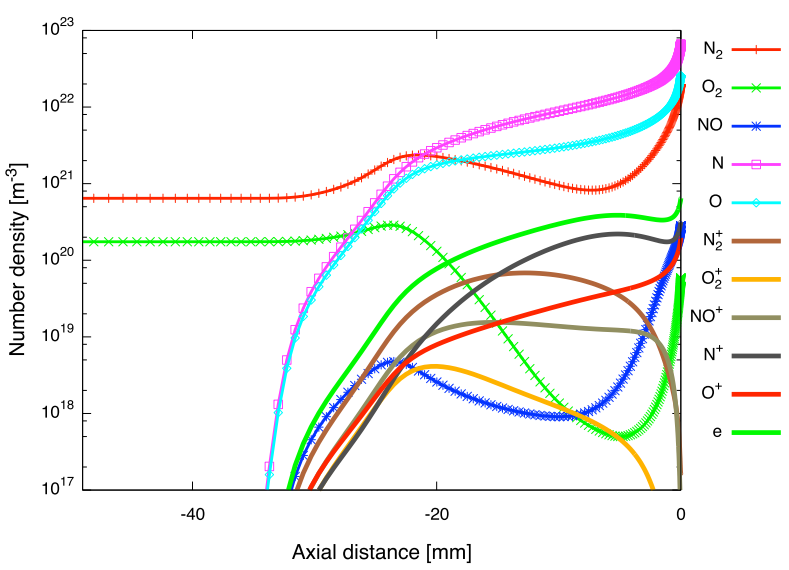

(c) Air species

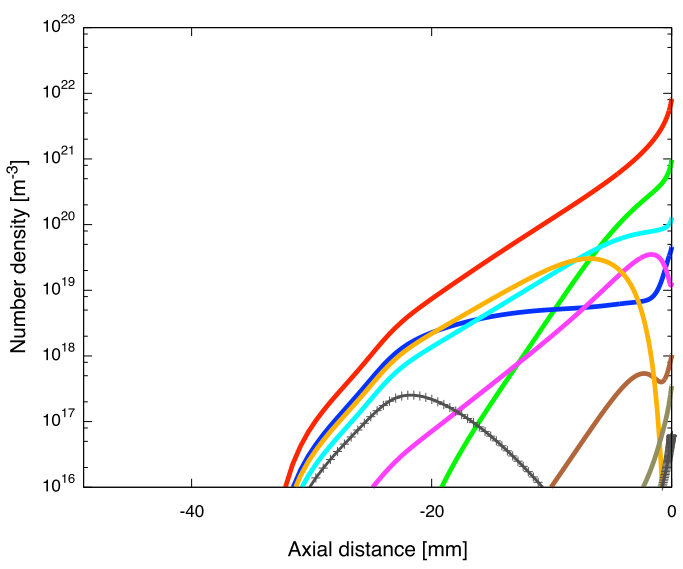

(e) High concentration species

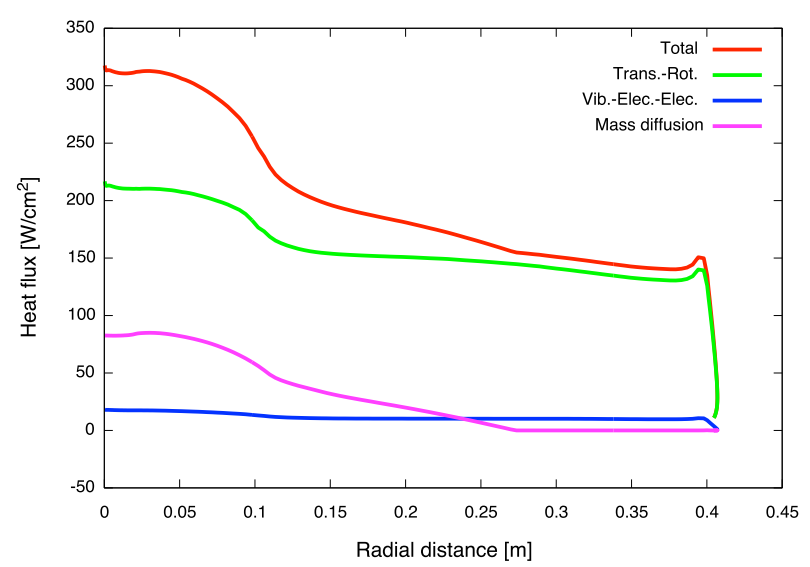

(b) Surface heat fluxes

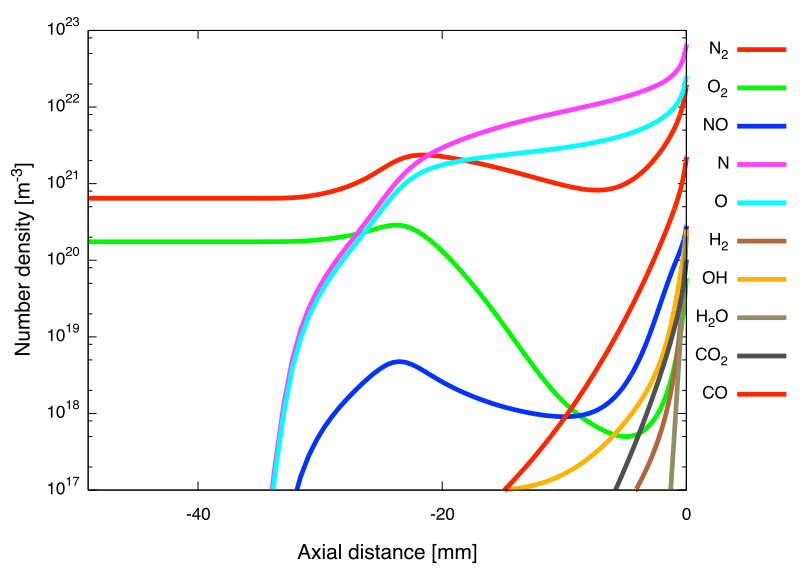

(d) Surface blowing species

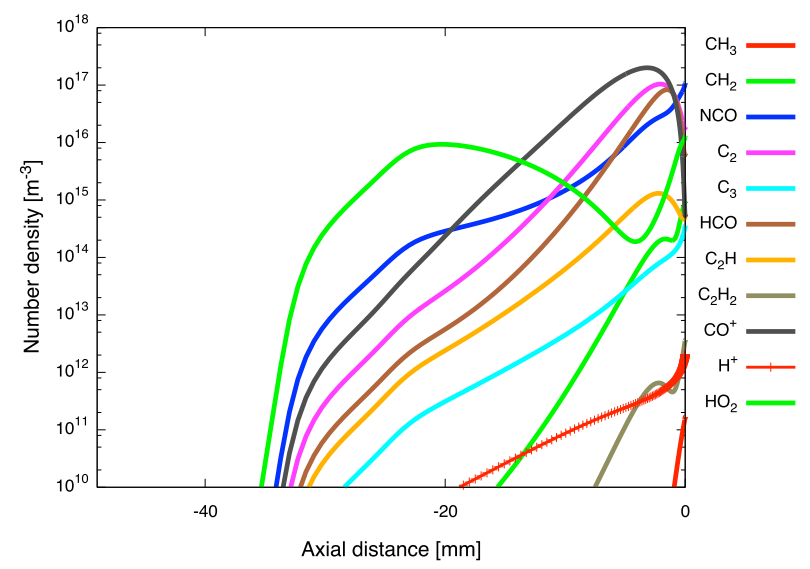

(f) Low concentration species

Figure 6. Species concentrations along the stagnation line for the Stardust re-entry vehicle at an altitude of $73.5 \mathrm{~km}$ (40 s into re-entry) 


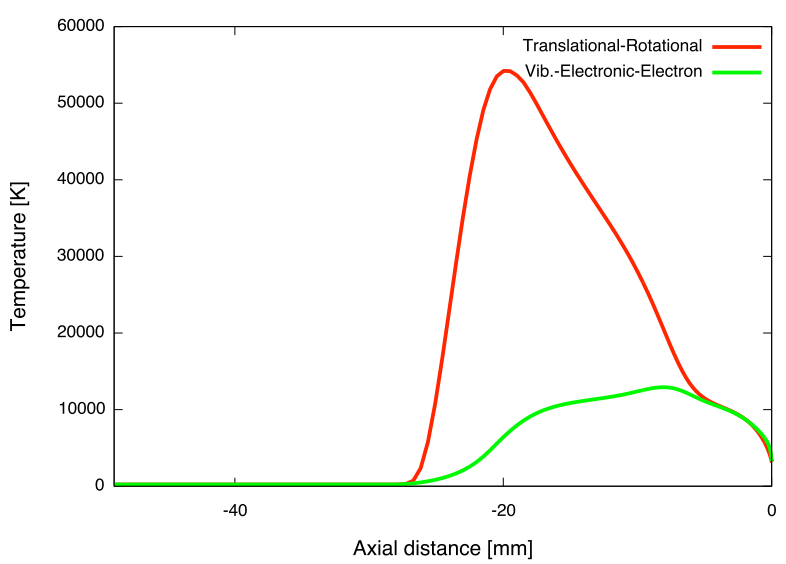

(a) Stagnation line temperatures

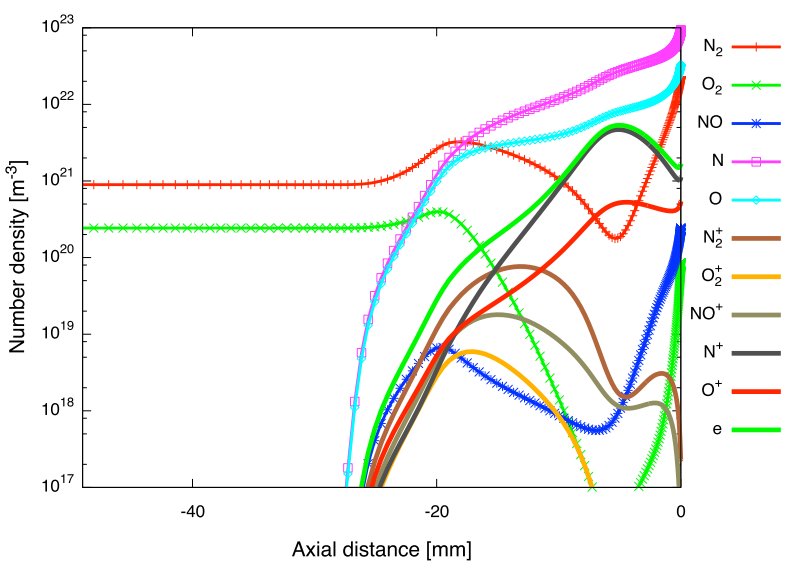

(c) Air species

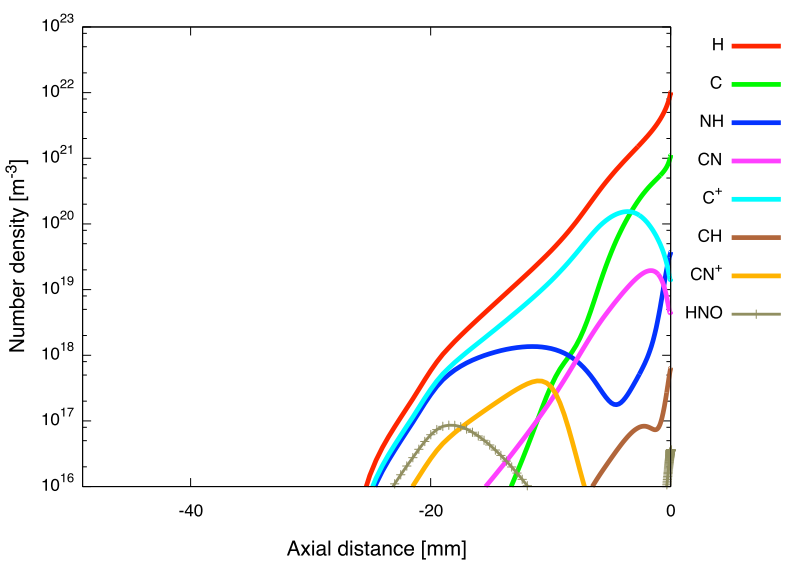

(e) High concentration species

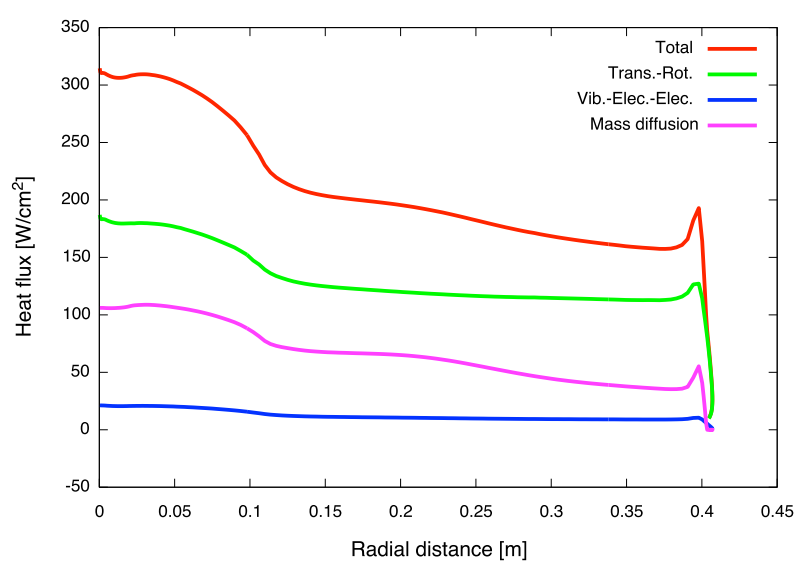

(b) Surface heat fluxes

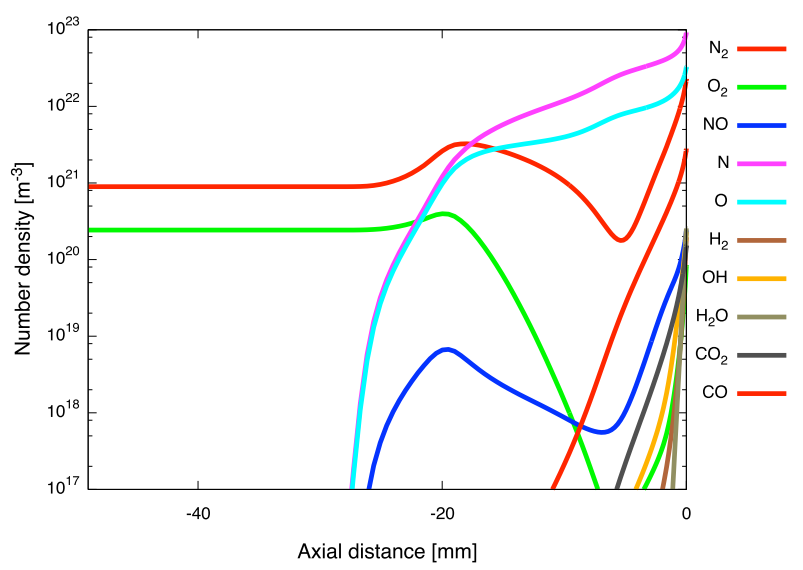

(d) Surface blowing species

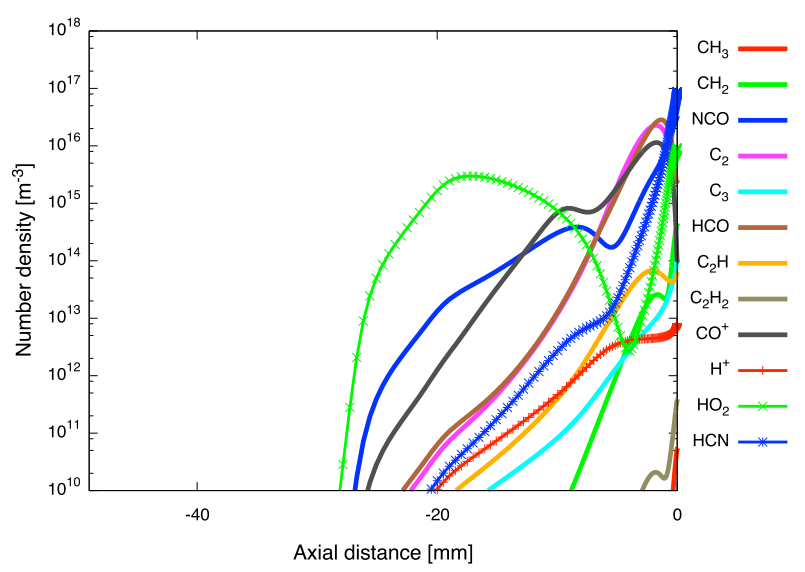

(f) Low concentration species

Figure 7. Species concentrations along the stagnation line for the Stardust re-entry vehicle at an altitude of $71 \mathrm{~km}(42$ s into re-entry) 


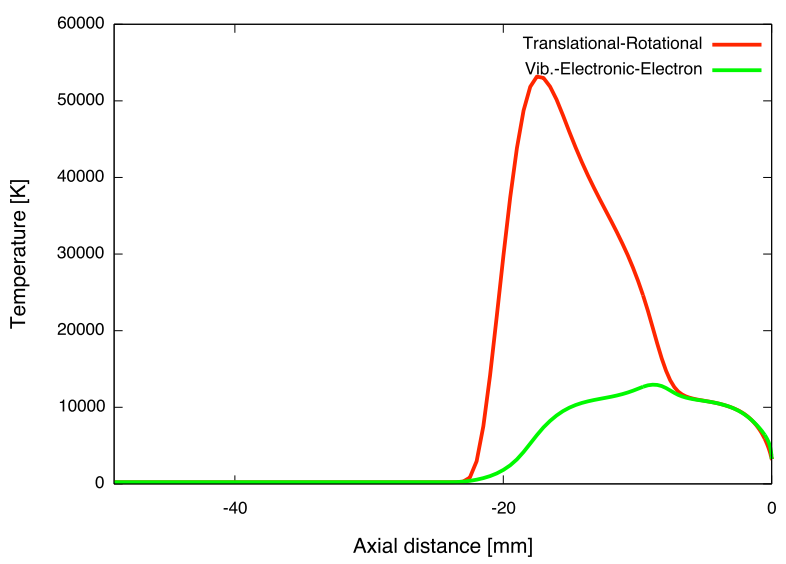

(a) Stagnation line temperatures

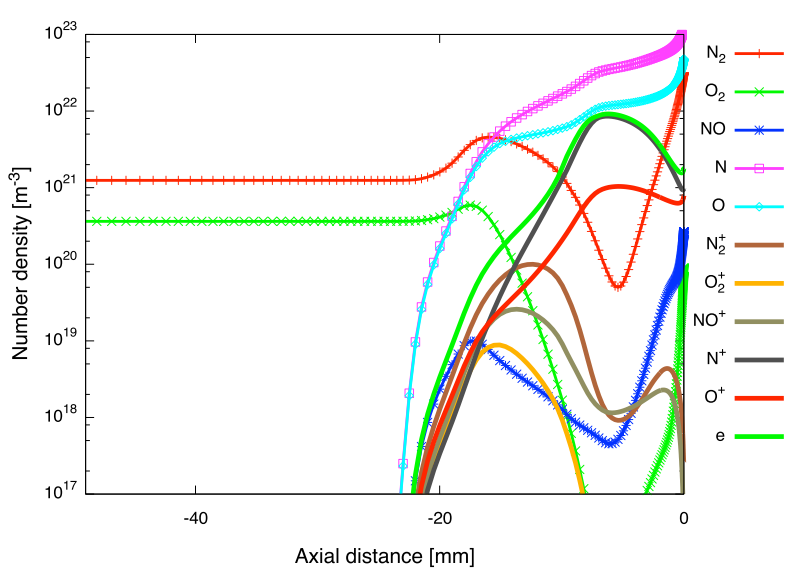

(c) Stagnation line air species concentration

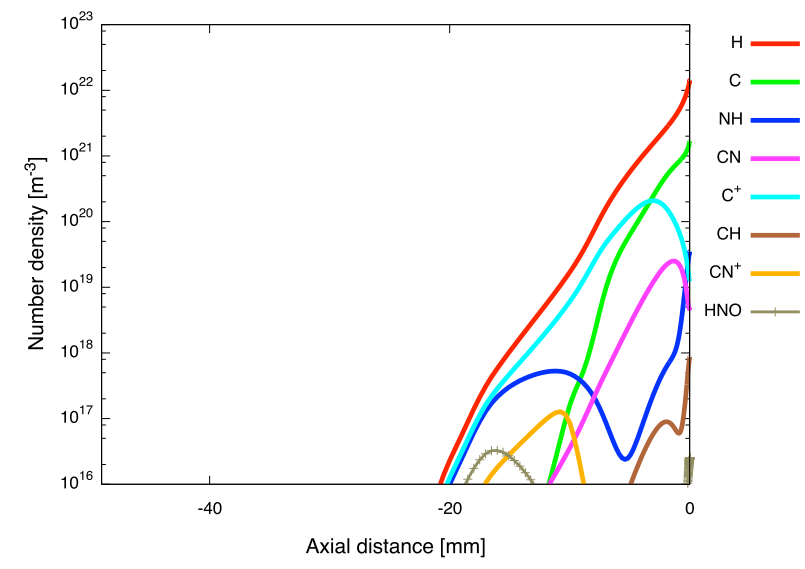

(e) Stagnation line high concentration species

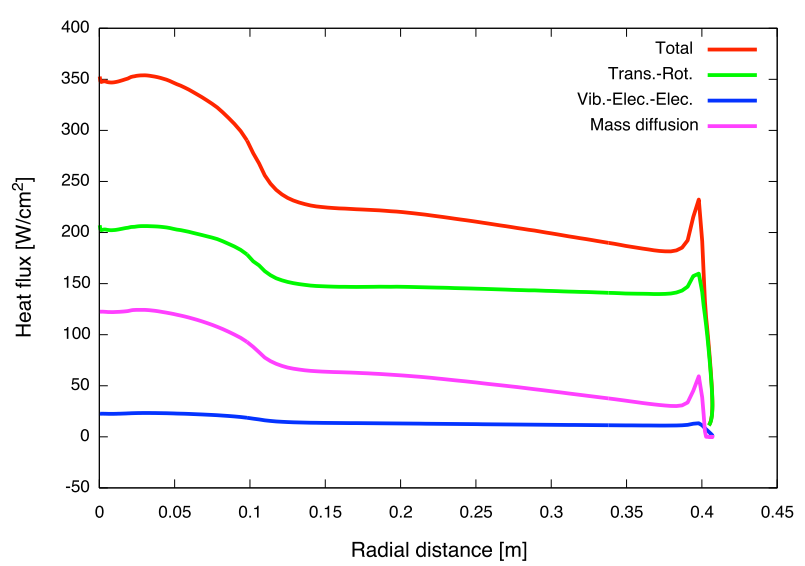

(b) Surface heat fluxes

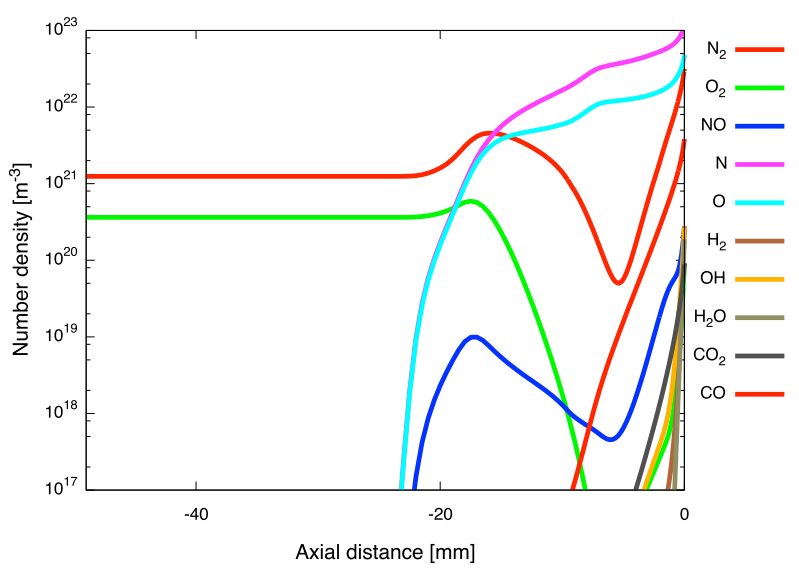

(d) Stagnation line surface blowing species concentration

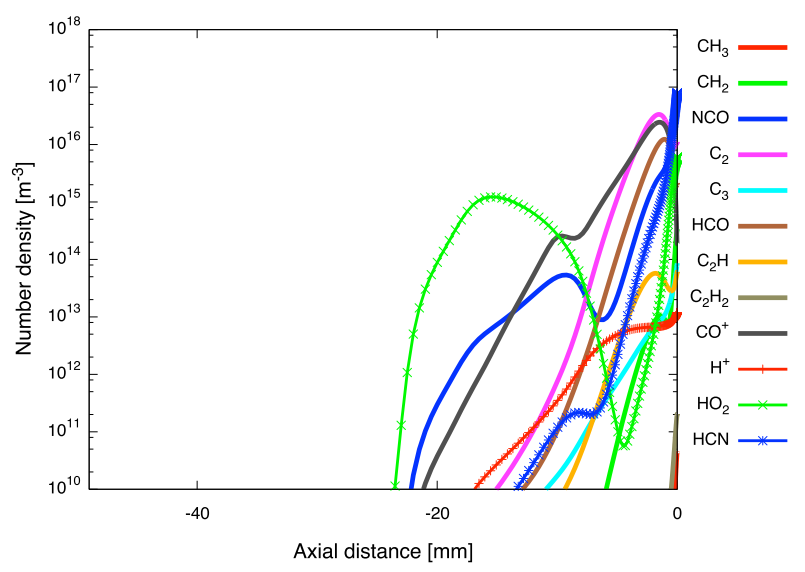

(f) Stagnation line low concentration species

Figure 8. Species concentrations along the stagnation line for the Stardust re-entry vehicle at an altitude of $68.9 \mathrm{~km}$ (44 s into re-entry) 


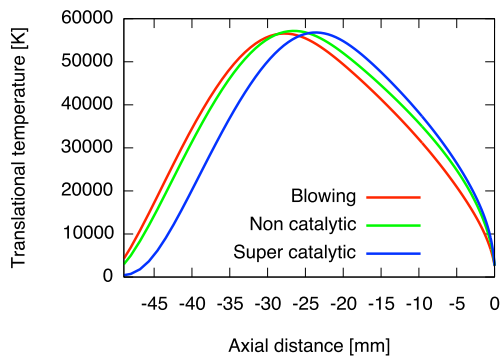

(a) Stagnation line trans.-rot. temperature

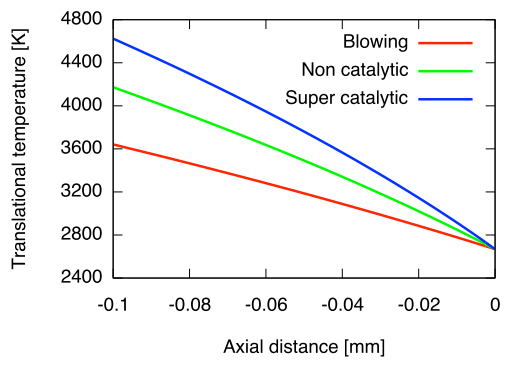

(b) Stagnation line trans.-rot. temperature near the wall

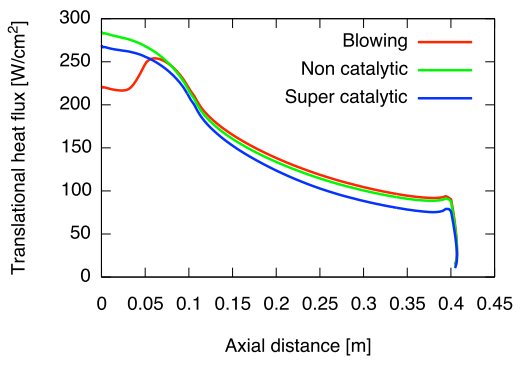

(c) Trans.-rot. energy heat flux

Figure 9. Blowing reduction effects on the translational-rotational energy at $81 \mathrm{~km}$

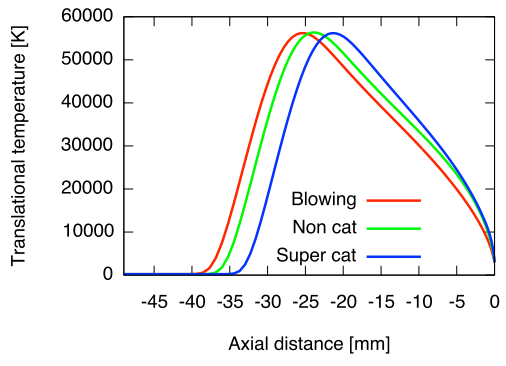

(a) Stagnation line trans.-rot. temperature

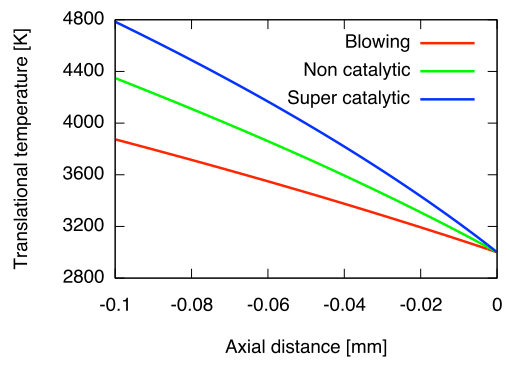

(b) Stagnation line trans.-rot. temperature near the wall

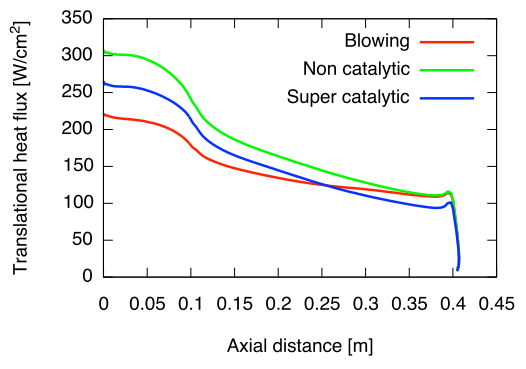

(c) Trans.-rot. energy heat flux

Figure 10. Blowing reduction effects on the translational-rotational energy at $76 \mathrm{~km}$

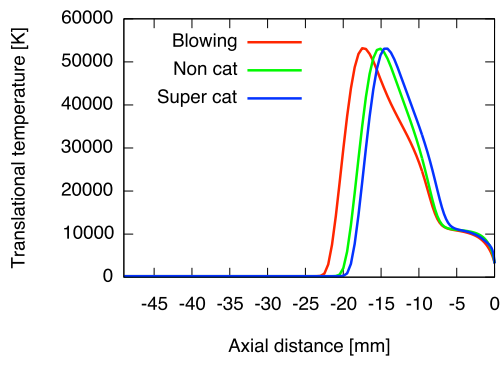

(a) Stagnation line trans.-rot. temperature

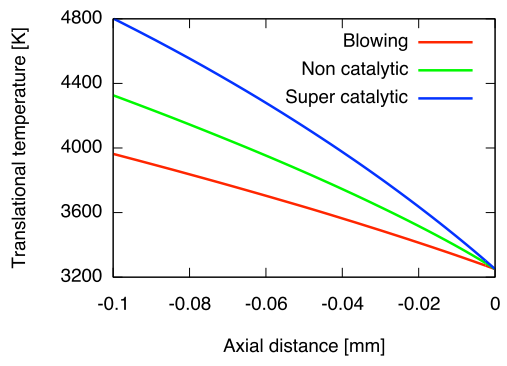

(b) Stagnation line trans.-rot. temperature near the wall

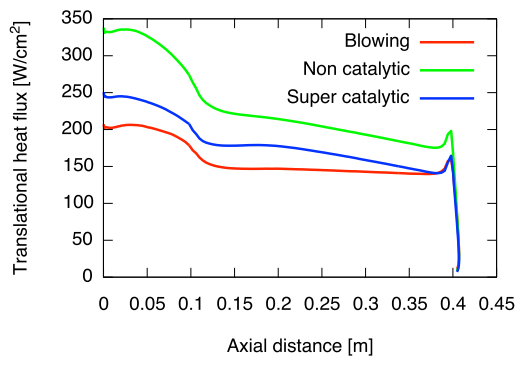

(c) Trans.-rot. energy heat flux

Figure 11. Blowing reduction effects on the translational-rotational energy at $68.9 \mathrm{~km}$ 


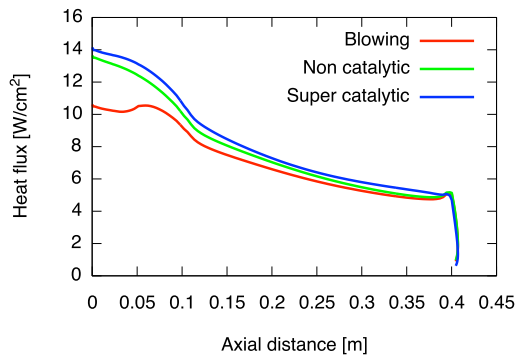

(a) Re-entry altitude of $81 \mathrm{~km}$

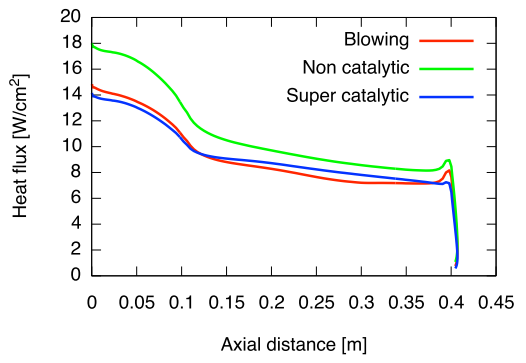

(b) Re-entry altitude of $76 \mathrm{~km}$

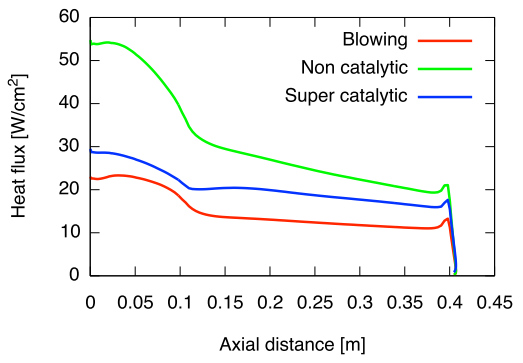

(c) Re-entry altitude of $68.9 \mathrm{~km}$

Figure 12. Blowing reduction effects on the vibrational-electronic-electron heat flux

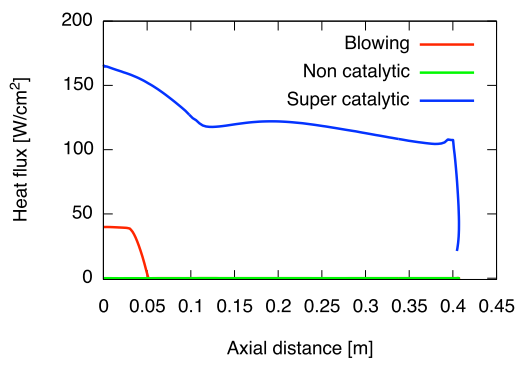

(a) Re-entry altitude of $81 \mathrm{~km}$

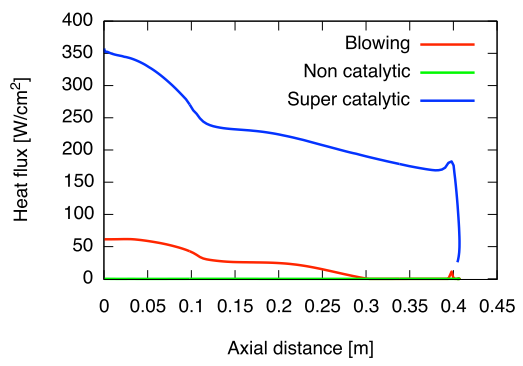

(b) Re-entry altitude of $76 \mathrm{~km}$

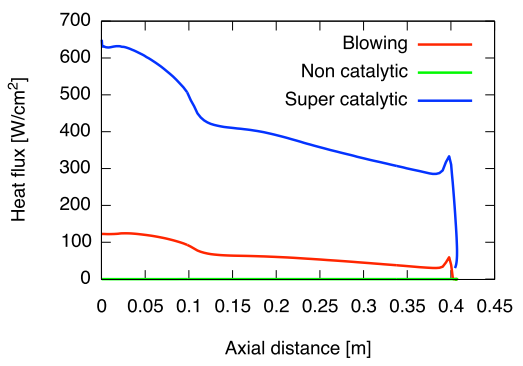

(c) Re-entry altitude of $68.9 \mathrm{~km}$

Figure 13. Blowing reduction effects on the mass diffusion heat flux

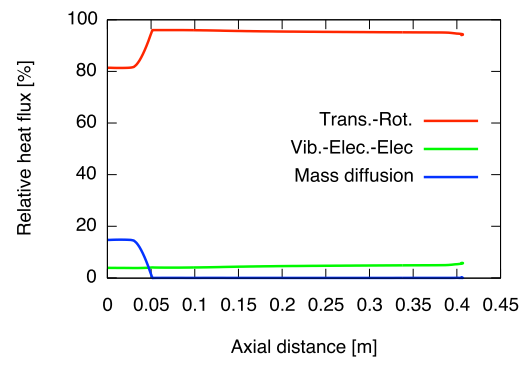

(a) Re-entry altitude of $81 \mathrm{~km}$

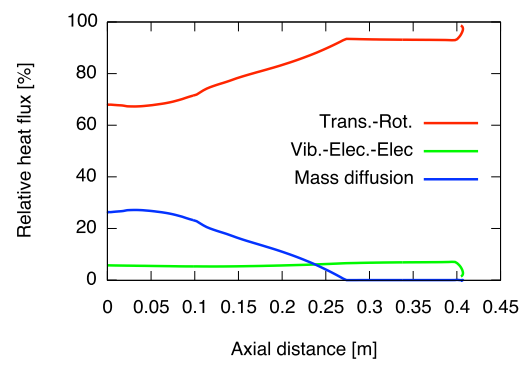

(d) Re-entry altitude of $73.5 \mathrm{~km}$

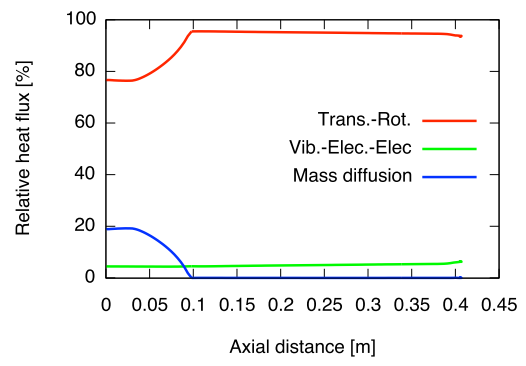

(b) Re-entry altitude of $78.5 \mathrm{~km}$

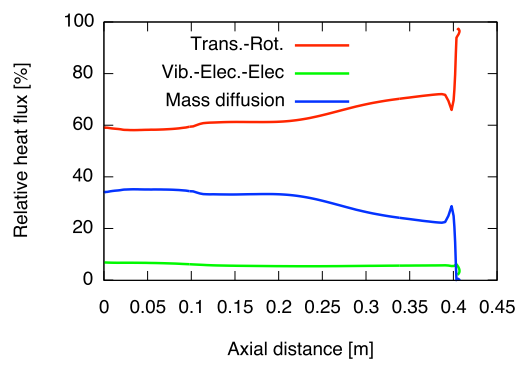

(e) Re-entry altitude of $71.2 \mathrm{~km}$

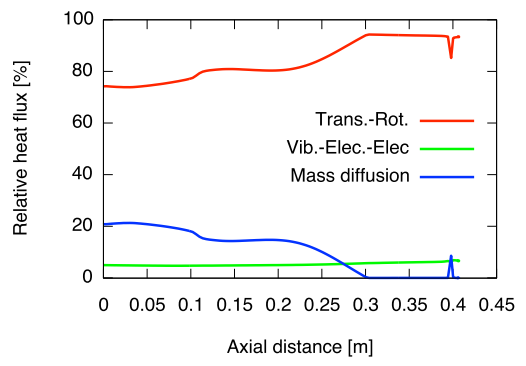

(c) Re-entry altitude of $76 \mathrm{~km}$

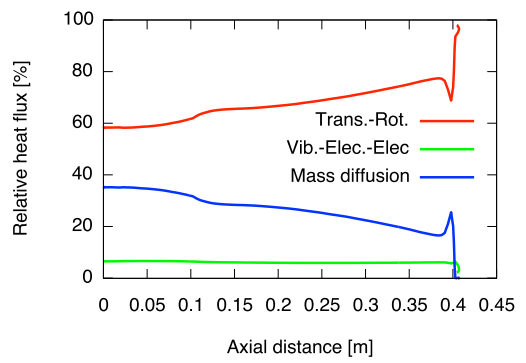

(f) Re-entry altitude of $68.9 \mathrm{~km}$

Figure 14. Relative contribution of individual components of the heat flux using the blowing boundary condition 


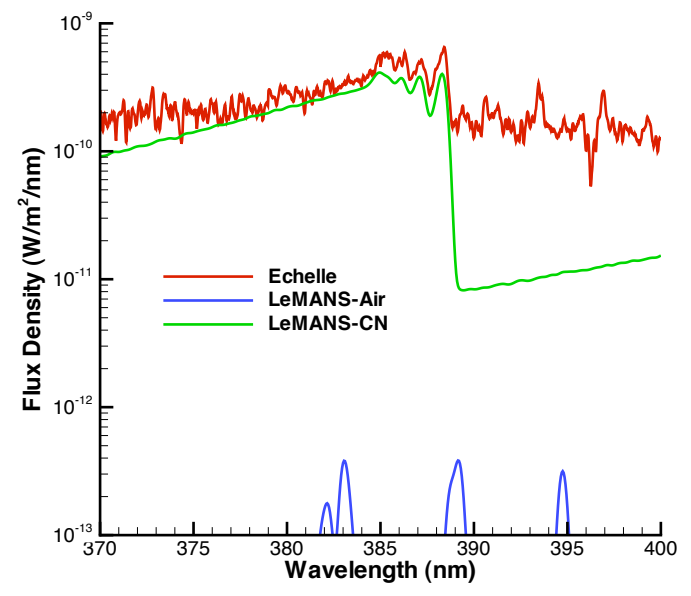

(a) $81 \mathrm{~km}: 34 \mathrm{~s}$ into re-entry

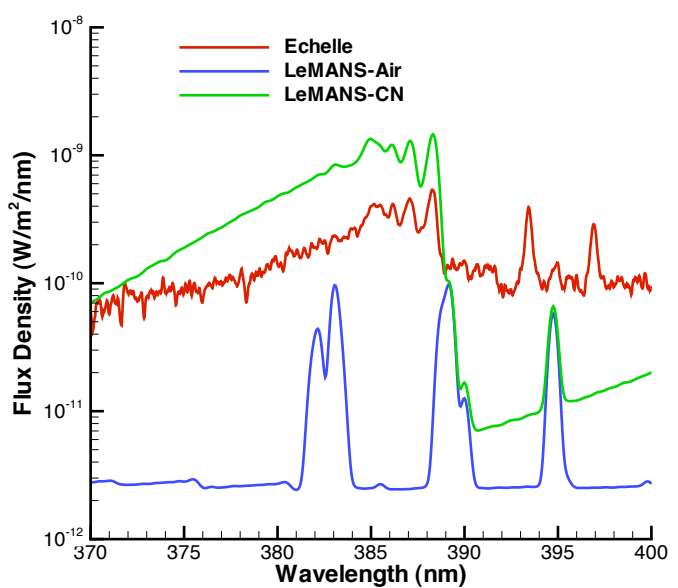

(b) $71 \mathrm{~km}: 44 \mathrm{~s}$ into re-entry

Figure 15. Spectral emission for the Startdust re-entry vehicle at $81 \mathrm{~km}$ and $71 \mathrm{~km}$ 